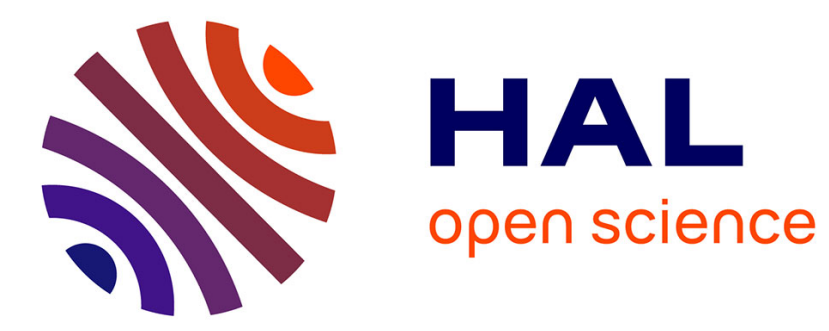

\title{
Education Choices, Longevity and Optimal Policy in a Ben-Porath Economy
}

Yukihiro Nishimura, Pierre Pestieau, Grégory Ponthière

\section{To cite this version:}

Yukihiro Nishimura, Pierre Pestieau, Grégory Ponthière. Education Choices, Longevity and Optimal Policy in a Ben-Porath Economy. 2015. halshs-01230932

\section{HAL Id: halshs-01230932 \\ https://shs.hal.science/halshs-01230932}

Preprint submitted on 19 Nov 2015

HAL is a multi-disciplinary open access archive for the deposit and dissemination of scientific research documents, whether they are published or not. The documents may come from teaching and research institutions in France or abroad, or from public or private research centers.
L'archive ouverte pluridisciplinaire HAL, est destinée au dépôt et à la diffusion de documents scientifiques de niveau recherche, publiés ou non, émanant des établissements d'enseignement et de recherche français ou étrangers, des laboratoires publics ou privés. 


\title{
PARISSCHOOL OF ECONOMICS
}

WORKING PAPER N $2015-40$

Education Choices, Longevity and Optimal Policy in a Ben-Porath Economy

\author{
Yukihiro Nishimura \\ Pierre Pestieau \\ Gregory Ponthiere
}

JEL Codes: E13, I25, I28, J10

Keywords: Education, Life expectancy, OLG models, Optimal policy

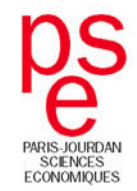




\title{
Education Choices, Longevity and Optimal Policy in a Ben-Porath Economy
}

\author{
Yukihiro Nishimura* Pierre Pestieau ${ }^{\dagger}$ Gregory Ponthiere ${ }^{\ddagger}$
}

November 16, 2015

\begin{abstract}
We develop a 3-period overlapping generations (OLG) model where individuals borrow at the young age to finance their education. Education does not only increase future wages, but, also, raises the duration of life, which, in turn, affects education choices, in line with Ben Porath (1967). We first identify conditions that guarantee the existence of a stationary equilibrium with perfect foresight. Then, we reexamine the conditions under which the Ben-Porath effect prevails, and emphasize the impact of human capital decay and preferences. We compare the laissez-faire with the social optimum, and show that the latter can be decentralized provided the laissez-faire capital stock corresponds to the one satisfying the modified Golden Rule. Finally, we introduce intracohort heterogeneity in the learning ability, and we show that, under asymmetric information, the second-best optimal non-linear tax scheme involves a downward distortion in the level of education of less able types, which, quite paradoxically, would reinforce the longevity gap in comparison with the laissez-faire.

Keywords: education, life expectancy, OLG models, optimal policy.

JEL codes: E13, I25, I28, J10.
\end{abstract}

\footnotetext{
${ }^{*}$ Graduate School of Economics, Osaka University.

${ }^{\dagger}$ University of Liege, CORE, Paris School of Economics and CEPR.

‡University Paris East (ERUDITE), Paris School of Economics and Institut universitaire de France. [corresponding author] Address: Ecole Normale Superieure, Building A, 2nd floor, Office 202, Boulevard Jourdan 48, 75014 Paris. E-mail: gregory.ponthiere@ens.fr
} 


\section{Introduction}

During the last decades, economists have paid a large attention to the relations between economic development and demographic trends. Within classical growth theory, a strong emphasis was laid on the link between population growth and economic growth. Whereas Solow (1956) emphasized the capital dilution effect, by which population growth reduces the sustainable level of capital and output per head, Samuelson (1975) emphasized, in an overlapping generations economy (OLG), that population growth can induce an age structure favorable for long-run standards of living (i.e. the intergenerational redistribution effect). The relation between population growth and development is also at the center of the literature on fertility choices, which examined trade-offs between the quantity and the quality of children, and, hence, between population growth and long-run development (Barro and Becker 1989, Ehrlich and Lui 1991). Besides those analyses, the endogenous growth literature emphasized the occurrence of scale effects arising thanks to externalities in production (Romer 1990) or in knowledge (Kremer 1993). Finally, in the recent unified growth theory, thresholds in population sizes play a key role in the explanation of regime shifts from the Malthusian to the Modern growth regime (Galor and Moav 2002, 2005).

More recently, a strong emphasis was laid on the impact of survival conditions on economic development. The general intuition behind that literature consists in the simple idea that an improvement of survival conditions, by increasing the expected life span of economic agents, is likely to modify their decisions, in such a way as to encourage the accumulation of physical capital (through a higher propensity to save) and the accumulation of human capital (through a longer enjoyment of education returns). The starting point of that literature is the seminal contribution by Ben Porath (1967). Ben Porath argued that a rise in life expectancy tends to increase the lifetime returns from educational investment, and, hence, tends to encourage individual investments in education. As a consequence of this effect, improvements in survival conditions are expected to lead to an increase in education, and, hence, to favor human capital accumulation and growth.

The so-called Ben-Porath effect has given rise, in the recent years, to a significant literature, both at the theoretical and empirical levels. On the theoretical side, a first group of articles examined the impact of an exogenous change in survival conditions on education and growth. Ehrlich and Lui (1991) showed, by means of a 3-period OLG model with endogenous fertility and education chosen by parents, that an improvement of survival conditions for children could, by reducing the chosen fertility, favor education investment and economic growth. On the basis of a OLG model with vintage human capital, Boucekkine et al (2002) showed that an improvement of survival conditions has three distinct effects on human capital accumulation and growth. First, better survival conditions increase the number of workers (i.e. pure quantity effect). Second, better survival conditions increase the expected lifespan during which workers can benefit from education returns, which favors higher education levels, and, hence, stimulates human capital accumulation and growth. This second effect is noth- 
ing less than the Ben-Porath effect. Third, better survival conditions increase the average age of workers, which reduces worker's average productivity (because of the depreciation of the skills), and has a negative effect on growth. The overall effect of an improvement of survival conditions varies with the relative sizes of those three effects. More recently, Ludwig and Vogel (2010) developed an OLG model with physical capital accumulation and risky lifetime to examine how aging can lead to increased educational efforts. They numerically showed that the effect of a changing lifetime labor supply tends to increase the optimal education, although the increase of effective labor decreases capital-labor ratio and hence has a dampening effect on education.

Still at the theoretical levels, recent papers examined the relation between education and life expectancy in a setting where not only does life expectancy affect education, but where education affects life expectancy. The underlying intuition is to focus not only on the effect of an exogenous change in survival conditions on education, but, rather, to study a system where higher education levels contribute to improve survival conditions, which, in turn, affect education decisions. As shown in several papers, the introduction of that feedback effect complicates the analysis of the Ben-Porath effect, and may lead to the occurrence of poverty and demographic traps (see Blackburn and Cipriani 2002, Chakraborty 2004, Cervelatti and Sunde 2005, Soares 2005). Several variants of that theoretical framework were developed, including, in particular, different assumptions regarding the education decision. Whereas de la Croix and Licandro (2013) develop a model where parents choose the quantity and the quality of their children (determining their longevity), Leker and Ponthiere (2015) study the Ben-Porath effect in an economy where education is determined by intrafamilial bargaining between parents and children.

On the empirical side, various studies aimed at testing whether life expectancy improvements affect economic growth. This effect may not be due to the Ben-Porath effect, since life expectancy may affect growth through other channels (e.g. saving). But the Ben-Porath effect could explain, in theory, a positive impact of life expectancy growth on economic growth. Bloom et al (2004) show that a 5-year increase in life expectancy generates a $21 \%$ rise of the growth rate. ${ }^{1}$ Acemoglu and Johnson (2007) found that, once adequate instruments are used to avoid endogeneity biases, life expectancy does not seem to affect economic growth. Hazan (2009) argued that the Ben-Porath effect can only arise provided additional life-years are years of occupation, which has not been observed. On the contrary, de la Croix et al (2009) find, for Sweden, that the longevity increase accounts for $20 \%$ of the rise in education over the last two centuries. More recently, Bloom et al (2013) have criticized Acemoglu and Johnson's approach, on the ground that they neglect the impact of initial conditions. Cervelatti and Sunde (2011) argued also against Acemoglu and Johnson (2007) that, once we take into account differences between countries in terms of fertility, it appears that life expectancy increases economic growth in countries

\footnotetext{
${ }^{1}$ Similar effects are found in Bloom and Sachs (1998), Bloom and Williamson (1998), and Gallup and Sachs (2001).
} 
having accomplished their demographic transition.

Those mixed empirical results suggest that, although the Ben-Porath effect is theoretically plausible, that effect is far from being universally observed. On the contrary, its size depends on various kinds of determinants. In particular, Hazan's (2009) criticism suggests that the plausibility of the Ben-Porath effect should be assessed in a theoretical model where the retirement age is not exogenous, but, rather, where individuals decide when they retire. Moreover, the fact that the occurrence of the Ben-Porath effect varies across countries suggests that more attention should be paid, when analyzing the Ben-Porath effect, to the impact of cultural factors, such as preferences, on educational choices.

Besides those theoretical and empirical studies on the Ben-Porath effect, little emphasis has been laid, so far, on the policy implications of the Ben-Porath effect. There have been few attempts to examine the design of the optimal subsidy on education in an economy where the Ben-Porath effect is at work. In particular, it is widely acknowledged that education constitutes a major vector of inequalities within the society, and that inequalities in life expectancy and in education are strongly related (see Deboosere et al. 2009). This connexion between education and life expectancy is conform with the Ben-Porath effect. But few attempts were made to derive the optimal public intervention in an economy where education and life expectancy are correlated.

The goal of this paper is twofold. Firstly, we propose to reexamine the BenPorath effect in a dynamic OLG model where individuals choose their education, their saving and the age at which they retire, and where the duration of their life depends on the amount of education. Following Boucekkine et al (2002), who emphasized that the Ben-Porath effect depends on the depreciation of human capital, we assume that there exists some decay of human capital, which may affect education decisions. We use that microeconomic model to identify the determinants of the Ben-Porath effect, and, in particular, the impact of preferences (attitudes towards risk and towards labor) on the Ben-Porath effect. Secondly, we use that setting to study the design of the optimal public policy in a Ben-Porath economy. For that purpose, we first consider the decentralization of the social optimum in an economy composed of homogeneous agents. Then, we introduce heterogeneity within cohorts regarding the learning ability of individuals, and we study the optimal public intervention in a second-best setting where individual learning ability is not observed by the government.

Anticipating on our results, we first identify, in our Ben-Porath economy, conditions that guarantee the existence of a stationary equilibrium with perfect foresight, and we compare those conditions in the cases of exogenous and endogenous longevity. Then, we reexamine the conditions under which the BenPorath effect prevails, and emphasize the impact of human capital decay and preferences. Here again, we distinguish between the cases where longevity is exogenous and where education increases longevity. We compare the laissezfaire with the social optimum, and show that the latter can be decentralized provided the laissez-faire capital stock corresponds to the one satisfying the modified Golden Rule. Finally, we introduce intracohort heterogeneity in the learning ability, and we show that, under asymmetric information, the second- 
best optimal non-linear tax scheme involves a downward distortion in the level of education of less able types, which, quite paradoxically, would reinforce the longevity gap in comparison with the laissez-faire.

The rest of the paper is organized as follows. Section 2 presents the model. The temporary equilibrium is characterized in Section 3. Section 4 studies the conditions under which a stationary equilibrium with perfect foresight exists. Section 5 examines, at the stationary equilibrium with perfect foresight, the determinants of the Ben-Porath effect. The social optimum is characterized in Section 6. Section 7 examines the second-best problem when the population is heterogeneous in terms of learning capacity. Section 8 concludes.

\section{The model}

Let us consider a three-period OLG model. Period 1 is childhood, during which children borrow in order to invest an amount $e$ in their higher education. During period 2, individuals work, pay back the cost of their education, consume and save some resources. Period 3 is the old age. Whereas the durations of periods 1 and 2 are normalized to unity, the duration of period 3 is equal to $\ell(0<\ell<1) .{ }^{2}$ During period 3, individuals work some fraction $z$ and consume their saving. For the sake of simplicity, we consider here an economy composed of identical individuals. $^{3}$

Demography Fertility is exogenous, and equal to its replacement level. There is no risk about the duration of life. Survival curves are perfectly rectangular. However, the duration of the old age varies over time, as a function of the educational level enjoyed during the childhood, according to the following function:

$$
\ell_{t+1}=\ell\left(e_{t-1}\right)
$$

where $\ell(0)=\ell>0, \ell^{\prime}\left(e_{t-1}\right)>0$ and $\ell^{\prime \prime}\left(e_{t-1}\right)<0$. We also assume that $\lim _{e_{t-1} \rightarrow 0} \ell^{\prime}\left(e_{t-1}\right)=+\infty, \lim _{e_{t-1} \rightarrow+\infty} \ell^{\prime}\left(e_{t-1}\right)=0$ and $\lim _{e_{t-1} \rightarrow \infty} \ell\left(e_{t-1}\right)=$ $\bar{\ell}<1$.

Production Production takes place with physical capital and effective labor, according to a production function with constant returns to scale:

$$
Y_{t}=F\left(K_{t}, L_{t}\right)
$$

where $K_{t}$ denotes the stock of capital at time $t$, while $L_{t}$ is the total amount of effective labor, equal to:

$$
L_{t}=h_{t} N_{t}+z_{t} \alpha h_{t-1} N_{t-1}
$$

\footnotetext{
${ }^{2}$ Alternatively, we could here consider survival probabilities dependent on education. This would imply introducing an annuity market. Further, it would face Bommier's critique of risk neutrality with respect to the length of life (see Bommier 2007).

${ }^{3}$ The case of heterogeneous individuals is discussed in Section 7 .
} 
and $F(\cdot)$ exhibits constant returns to scale, $h_{t} N_{t}$ is the number of effective labor units from young workers at time $t$, where $h_{t}$ denotes the stock of human capital for each young worker at time $t$, and $N_{t}$ is the number of young workers at time $t$. Moreover, $z_{t} \alpha h_{t-1} N_{t-1}$ amounts to the number of effective labor units from old workers at time $t$. This number depends on the retirement age $z_{t}$, as well as on the human capital decay, which is captured by the parameter $\alpha$. When there is no decay, we have $\alpha=1$. On the contrary, when there is some strong decay, $\alpha$ is close to 0 . Under CRS, and given $N_{t-1}=N_{t}=N$, the production process can be written as:

$$
\tilde{y}_{t}=\frac{Y_{t}}{N}=F\left(\tilde{k}_{t}, h_{t}+z_{t} \alpha h_{t-1}\right)
$$

where $\tilde{y}_{t} \equiv \frac{Y_{t}}{N}$ is the output per young worker and $\tilde{k}_{t} \equiv \frac{K_{t}}{N}$ is the capital per young worker.

Physical capital and borrowing for children's education investment are financed on the basis of individual saving. We assume that capital fully depreciates after one period of use. Given that only the young save for their old days, the capital-market clearing condition takes, in aggregated terms, the form:

$$
K_{t+1}+N e_{t}=N s_{t}
$$

Let us define capital per effective working unit as $k_{t} \equiv \frac{K_{t}}{L_{t}}$. Hence we have:

$$
k_{t+1}=\frac{K_{t+1}}{N h\left(e_{t-1}\right)+N z_{t} \alpha h\left(e_{t-2}\right)}
$$

We can thus rewrite the capital accumulation equation in per effective working units terms as:

$$
\begin{aligned}
k_{t+1} & =\frac{N\left(s_{t}-e_{t}\right)}{N h\left(e_{t-1}\right)+N z_{t} \alpha h\left(e_{t-2}\right)} \\
& =\frac{s_{t}-e_{t}}{h\left(e_{t-1}\right)+z_{t} \alpha h\left(e_{t-2}\right)}
\end{aligned}
$$

where $s_{t}$ denotes the saving of each young adult.

Regarding the accumulation of human capital, we assume that the level of human capital depends on the amount of education investment at the young age, according to the relation:

$$
h_{t}=h\left(e_{t-1}\right)
$$

with $h(0)=1, h^{\prime}\left(e_{t-1}\right)>0$ and $h^{\prime \prime}\left(e_{t-1}\right)<0$. An investment $e_{t}$ in education at the young age yields a human capital $h_{t}$ equal to $h\left(e_{t-1}\right)$ at the young age, and a human capital $\alpha h\left(e_{t-1}\right)$ at the old age. We assume also that $\lim _{e_{t-1} \rightarrow 0} h^{\prime}\left(e_{t-1}\right)=+\infty$ and that $\lim _{e_{t-1} \rightarrow+\infty} h^{\prime}\left(e_{t-1}\right)=0$.

The economy is perfectly competitive. Workers and capital holders take the market prices as given. The wage rate $w_{t}$ is equal to the marginal productivity 
of labor, whereas the interest factor $R_{t}$ is equal to the marginal productivity of capital:

$$
\begin{aligned}
& w_{t}=F_{L}\left(K_{t}, L_{t}\right) \\
& R_{t}=F_{K}\left(K_{t}, L_{t}\right)
\end{aligned}
$$

Given CRS, we have that $F\left(K_{t}, L_{t}\right)=L_{t} F\left(\frac{K_{t}}{L_{t}}, 1\right)=L_{t} f\left(k_{t}\right)$, so that:

$$
\begin{aligned}
& w_{t}=F_{L}\left(K_{t}, L_{t}\right)=f\left(k_{t}\right)-k_{t} f^{\prime}\left(k_{t}\right) \\
& R_{t}=F_{K}\left(K_{t}, L_{t}\right)=f^{\prime}\left(k_{t}\right) .
\end{aligned}
$$

We assume that $\lim _{k \rightarrow 0} f^{\prime}(k)=+\infty$ and $\lim _{k \rightarrow+\infty} f^{\prime}(k)=0$.

Preferences Individuals derive some welfare from consumption during periods 2 and 3 . There is no direct disutility of education, in the sense that the only disutility from education comes from the foregone consumption due to financing education at the young age. At the old age, there is some disutility of labor. For the sake of analytical convenience, individual lifetime welfare for a young adult at time $t$ is represented by the following function:

$$
U_{t}=u\left(c_{t}\right)+\ell_{t+1} u\left(d_{t+1}\right)
$$

where $c_{t}$ denotes consumption in period 2 , and $d_{t+1}$ denotes consumption at the old age. It is defined as:

$$
d_{t+1}=\frac{\tilde{d}_{t+1}-v\left(z_{t+1}, \ell_{t+1}\right)}{\ell_{t+1}}
$$

where $\tilde{d}_{t+1}$ denotes the material resources consumed in period 3 , whereas $v\left(z_{t+1}, \ell_{t+1}\right)$ denotes the disutility of old-age labor, which is here expressed in monetary terms, as something that reduces the amount of consumption enjoyed at the old age.

It is assumed that the monetary disutility of old-age labor is increasing in the retirement age $z_{t+1}$, and decreasing with the duration of the old age $\ell_{t+1}$. The underlying intuition is that the shorter the old-age, the larger is the disutility from old age labor. On the contrary, the longer the old age, the lower is the disutility of old age labor. We thus have: $v_{z}\left(z_{t+1}, \ell_{t+1}\right)>0, v_{z z}\left(z_{t+1}, \ell_{t+1}\right)>0$, and $v_{\ell}\left(z_{t+1}, \ell_{t+1}\right)<0$. For the sake of simplicity, we will use the following quadratic function for the disutility of old-age labor:

$$
v\left(z_{t+1}, \ell_{t+1}\right)=\frac{\left(z_{t+1}\right)^{2}}{2 \gamma \ell_{t+1}}
$$

where $\gamma>0$ reflects the more or less large marginal disutility of old-age labor. We have $v_{\ell}\left(z_{t+1}, \ell_{t+1}\right)=\frac{-\left(z_{t+1}\right)^{2} 2 \gamma}{\left(2 \gamma \ell_{t+1}\right)^{2}}$ and $v_{\ell \ell}\left(z_{t+1}, \ell_{t+1}\right)=\frac{\left(z_{t+1}\right)^{2} 2 \gamma 2\left(2 \gamma \ell_{t+1}\right) 2 \gamma}{\left(2 \gamma \ell_{t+1}\right)^{4}}>$ 0 . 
Resource constraints Young individuals need to borrow to finance their education, and need thus to pay this back when they start to work. Denoting the interest factor by $R_{t}$, the budget constraint at the young age can be written as:

$$
c_{t}=w_{t} h\left(e_{t-1}\right)-e_{t-1} R_{t}-s_{t}
$$

whereas the budget constraint at the old age is:

$$
\tilde{d}_{t+1}=z_{t+1} \alpha w_{t+1} h\left(e_{t-1}\right)+R_{t+1} s_{t}
$$

\section{Temporary equilibrium}

This section characterizes the temporary equilibrium of our economy. For that purpose, we will proceed in two stages. We will first consider the case where longevity is exogenous, and, then, the case where longevity is endogenous.

In each case, individuals choose the education investment, their saving as well as their retirement age, conditionally on their resource constraints, and conditionally on some beliefs regarding future factor prices (wages and interest rates), with superscript $e$.

\subsection{Exogenous longevity}

In the case where longevity is purely exogenous, i.e. $\ell_{t}=\bar{\ell}$, the problem of agents can be written as:

$\max _{e_{t-1}, s_{t}, z_{t+1}} u\left[w_{t} h\left(e_{t-1}\right)-e_{t-1} R_{t}-s_{t}\right]+\bar{\ell} u\left[\frac{z_{t+1} \alpha w_{t+1}^{e} h\left(e_{t-1}\right)-v\left(z_{t+1}, \bar{\ell}\right)+R_{t+1}^{e} s_{t}}{\bar{\ell}}\right]$

The first-order conditions (FOCs) are:

$$
\begin{aligned}
u^{\prime}\left(c_{t}\right) & =R_{t+1}^{e} u^{\prime}\left(d_{t+1}\right) \\
\alpha w_{t+1}^{e} h\left(e_{t-1}\right) & =v_{z}\left(z_{t+1}, \bar{\ell}\right) \\
u^{\prime}\left(d_{t+1}\right)\left[z_{t+1} \alpha w_{t+1}^{e} h^{\prime}\left(e_{t-1}\right)\right] & =u^{\prime}\left(c_{t}\right)\left[R_{t}-w_{t} h^{\prime}\left(e_{t-1}\right)\right]
\end{aligned}
$$

Hence we have:

$$
\begin{aligned}
u^{\prime}\left(c_{t}\right) & =R_{t+1}^{e} u^{\prime}\left(d_{t+1}\right) \\
z_{t+1} & =\alpha w_{t+1}^{e} h\left(e_{t-1}\right) \gamma \bar{\ell} \\
R_{t+1}^{e} w_{t} h^{\prime}\left(e_{t-1}\right)+\alpha^{2}\left(w_{t+1}^{e}\right)^{2} h\left(e_{t-1}\right) \gamma \bar{\ell} h^{\prime}\left(e_{t-1}\right) & =R_{t+1}^{e} R_{t}
\end{aligned}
$$

The last condition equalizes the marginal welfare gains from extending education investment with the marginal cost of education. The marginal welfare gain from increasing education concerns both periods 2 and 3, and goes through two channels. On the one hand, a higher education level increases the level of hourly labor earnings in periods 2 and 3, for a given retirement age in period 3. Note that, in period 3, that effect is mitigated by the decay of human capital. On the other hand, a higher education level tends to increase the retirement age in period 3. 
Proposition 1 Given the anticipated levels of future factor prices $w_{t+1}^{e}$ and $R_{t+1}^{e}$, the temporary equilibrium under exogenous longevity is a vector $\left(e_{t-1}, c_{t}, s_{t}, d_{t+1}, z_{t+1}, w_{t}, R_{t}, K_{t}, L_{t}\right)$ satisfying the conditions:

$$
\begin{aligned}
c_{t} & =w_{t} h\left(e_{t-1}\right)-e_{t-1} R_{t}-s_{t} \\
d_{t+1} & =\frac{z_{t+1} \alpha w_{t+1}^{e} h\left(e_{t-1}\right)+R_{t+1} s_{t}-v\left(z_{t+1}, \bar{\ell}\right)}{\bar{\ell}} \\
u^{\prime}\left(c_{t}\right) & =R_{t+1}^{e} u^{\prime}\left(d_{t+1}\right) \\
z_{t+1} & =\alpha w_{t+1}^{e} h\left(e_{t-1}\right) \gamma \bar{\ell} \\
R_{t+1}^{e} R_{t} & =h^{\prime}\left(e_{t-1}\right)\left[\alpha^{2}\left(w_{t+1}^{e}\right)^{2} h\left(e_{t-1}\right) \gamma \bar{\ell}+R_{t+1}^{e} w_{t}\right] \\
L_{t} & =h_{t}\left(e_{t-1}\right) N_{t}+z_{t} \alpha h_{t-1}\left(e_{t-2}\right) N_{t-1} \\
K_{t} & =N\left(s_{t-1}-e_{t-1}\right) \\
w_{t} & =F_{L}\left(K_{t}, L_{t}\right) \\
R_{t} & =F_{K}\left(K_{t}, L_{t}\right)
\end{aligned}
$$

If $\lim _{e_{t-1} \rightarrow 0} h^{\prime}\left(e_{t-1}\right)=+\infty$ and $\lim _{e_{t-1} \rightarrow+\infty} h^{\prime}\left(e_{t-1}\right)=0$, there exists an interior optimal level of $e_{t-1}$.

If $h\left(e_{t-1}\right)$ satisfies $\frac{\left|h^{\prime \prime}\left(e_{t-1}\right)\right|}{h^{\prime}\left(e_{t-1}\right)}>\frac{h^{\prime}\left(e_{t-1}\right)}{h\left(e_{t-1}\right)}$ for all $e_{t-1}$, then that interior optimal level for $e_{t-1}$ is unique.

Proof. See the Appendix.

Proposition 1 states conditions that guarantee that the optimal education level is interior and is unique. Note that, whereas the interiority conditions constitute some form of classical Inada conditions, the uniqueness condition is far stronger. To illustrate this, let us take the case of an isoelastic function $h\left(e_{t-1}\right)$, satisfying $h(0)=1, h^{\prime}(\cdot)>0$ and $h^{\prime \prime}(\cdot)<0$. We have:

$$
h\left(e_{t-1}\right)=\frac{e_{t-1}^{1-\phi}}{1-\phi}+1
$$

with $0<\phi<1$. The derivatives yield:

$$
\begin{aligned}
h^{\prime}\left(e_{t-1}\right) & =e_{t-1}^{-\phi}>0 \\
h^{\prime \prime}\left(e_{t-1}\right) & =-\phi e_{t-1}^{-\phi-1}<0
\end{aligned}
$$

Hence the uniqueness condition requires:

$$
\phi e_{t-1}^{-\phi-1}\left(\frac{e_{t-1}^{1-\phi}}{1-\phi}+1\right)>e_{t-1}^{-2 \phi} .
$$

This is equivalent to:

$$
e_{t-1}^{\phi-1}>\left[\frac{1-2 \phi}{\phi(1-\phi)}\right]
$$


which is true for all levels of $e_{t-1}^{\phi-1}$ when $\phi>1 / 2$. However, if $\phi \leq 1 / 2$, then the RHS exceeds the LHS for $e_{t-1}$ sufficiently large.

Hence, the condition on $h\left(e_{t-1}\right)$ guaranteeing the uniqueness of the optimal education level is not trivial. Whereas this result may seem surprising given the simplicity of the assumption, remind that the FOC for optimal education is:

$$
h^{\prime}\left(e_{t-1}\right)\left[\alpha^{2}\left(w_{t+1}^{e}\right)^{2} h\left(e_{t-1}\right) \gamma \bar{\ell}+R_{t+1}^{e} w_{t}\right]=R_{t+1}^{e} R_{t}
$$

Given the product $h^{\prime}\left(e_{t-1}\right)\left[\alpha^{2}\left(w_{t+1}^{e}\right)^{2} h\left(e_{t-1}\right) \gamma \bar{\ell}+R_{t+1}^{e} w_{t}\right]$ on the LHS of that condition, it is not so surprising that, for a given RHS, various levels of education $e_{t-1}$ can satisfy that condition. When $e_{t-1}$ increases, $h^{\prime}\left(e_{t-1}\right)$ decreases, but $h\left(e_{t-1}\right)$ increases. Hence, without imposing conditions on $h\left(e_{t-1}\right)$, it seems difficult to guarantee the uniqueness of the optimal education level. The condition $\left|h^{\prime \prime}\left(e_{t-1}\right)\right| h\left(e_{t-1}\right)>\left[h^{\prime}\left(e_{t-1}\right)\right]^{2}$ guarantees that the LHS of the FOC is strictly decreasing in $e_{t-1}$ for all levels of $e_{t-1}$, and, hence, guarantees the uniqueness of the level of $e_{t-1}$ for which the LHS equals the RHS of the FOC.

\subsection{Endogenous longevity}

The problem faced by the individual is now:

$$
\max _{e_{t-1}, s_{t}, z_{t+1}}\left\{\begin{array}{l}
u\left[w_{t} h\left(e_{t-1}\right)-e_{t-1} R_{t}-s_{t}\right] \\
+\ell\left(e_{t-1}\right) u\left[\frac{z_{t+1} \alpha w_{t+1}^{e} h\left(e_{t-1}\right)-v\left(z_{t+1}, \ell\left(e_{t-1}\right)\right)+R_{t+1}^{e} s_{t}}{\ell\left(e_{t-1}\right)}\right]
\end{array}\right\}
$$

FOCs are:

$$
\begin{aligned}
u^{\prime}\left(c_{t}\right)= & R_{t+1}^{e} u^{\prime}\left(d_{t+1}\right) \\
\alpha w_{t+1}^{e} h\left(e_{t-1}\right)= & v_{z}\left(z_{t+1}, \ell\left(e_{t-1}\right)\right) \\
u^{\prime}\left(c_{t}\right)\left[R_{t}-w_{t} h^{\prime}\left(e_{t-1}\right)\right]= & \ell^{\prime}\left(e_{t-1}\right) u\left(d_{t+1}\right) \\
& +u^{\prime}\left(d_{t+1}\right)\left[\begin{array}{c}
z_{t+1} \alpha w_{t+1}^{e} h^{\prime}\left(e_{t-1}\right) \\
-v_{\ell}\left(z_{t+1}, \ell\left(e_{t-1}\right)\right) \ell^{\prime}\left(e_{t-1}\right)
\end{array}\right] \\
& -u^{\prime}\left(d_{t+1}\right) \frac{\ell^{\prime}\left(e_{t-1}\right)}{\ell\left(e_{t-1}\right)}\left[\begin{array}{c}
z_{t+1} \alpha w_{t+1}^{e} h\left(e_{t-1}\right) \\
-v\left(z_{t+1}, \ell\left(e_{t-1}\right)\right)+R_{t+1}^{e} s_{t}
\end{array}\right]
\end{aligned}
$$

Hence we have:

$$
\begin{aligned}
u^{\prime}\left(c_{t}\right)= & R_{t+1}^{e} u^{\prime}\left(d_{t+1}\right) \\
z_{t+1}= & \alpha w_{t+1}^{e} h\left(e_{t-1}\right) \gamma \ell\left(e_{t-1}\right) \\
u^{\prime}\left(c_{t}\right)\left[R_{t}-w_{t} h^{\prime}\left(e_{t-1}\right)\right]= & u^{\prime}\left(d_{t+1}\right) z_{t+1} \alpha w_{t+1}^{e} h^{\prime}\left(e_{t-1}\right) \\
& +\ell^{\prime}\left(e_{t-1}\right)\left[\begin{array}{c}
u\left(d_{t+1}\right)-u^{\prime}\left(d_{t+1}\right) d_{t+1} \\
-u^{\prime}\left(d_{t+1}\right) v_{\ell}\left(z_{t+1}, \ell\left(e_{t-1}\right)\right)
\end{array}\right]
\end{aligned}
$$

Note here an additional determinant of the optimal education time. Unlike under exogenous longevity, a higher amount of education raises $\ell\left(e_{t-1}\right)$, which 
constitutes an additional motive for spending on education, provided the terms in brackets are positive, which is generally assumed in the literature.

Let us denote $F^{R} \equiv \frac{u^{\prime}(d) d}{u(d)} . F^{R}$ is called the fear of ruin, which is a measure of risk aversion often used in the literature of the value of life (see Eeckhoudt and Pestieau (2008)). In the following, we assume that $F^{R}$ is a positive constant. It is generally assumed to be less than unity $\left(0<F^{R}<1\right)$.

The FOC for education can be rewritten as:

$$
\begin{aligned}
& h^{\prime}\left(e_{t-1}\right)\left[\alpha^{2}\left(w_{t+1}^{e}\right)^{2} h\left(e_{t-1}\right) \gamma \ell\left(e_{t-1}\right)+R_{t+1}^{e} w_{t}\right] \\
& +\ell^{\prime}\left(e_{t-1}\right)\left[d_{t+1}\left(\frac{1}{F^{R}}-1\right)-v_{\ell}\left(z_{t+1}, \ell\left(e_{t-1}\right)\right)\right] \\
= & R_{t+1}^{e} R_{t}
\end{aligned}
$$

Proposition 2 characterizes the temporary equilibrium under endogenous longevity.

Proposition 2 Given the anticipated levels of future factor prices $w_{t+1}^{e}$ and $R_{t+1}^{e}$, the temporary equilibrium under endogenous longevity is a vector

$\left(e_{t-1}, c_{t}, s_{t}, d_{t+1}, z_{t+1}, w_{t}, R_{t}, K_{t}, L_{t}\right)$ satisfying the conditions:

$$
\begin{aligned}
& c_{t}=w_{t} h\left(e_{t-1}\right)-e_{t-1} R_{t}-s_{t} \\
& d_{t+1}=\frac{z_{t+1} \alpha w_{t+1}^{e} h\left(e_{t-1}\right)+R_{t+1} s_{t}-v\left(z_{t+1}, \ell\left(e_{t-1}\right)\right)}{\ell\left(e_{t-1}\right)} \\
& u^{\prime}\left(c_{t}\right)=R_{t+1}^{e} u^{\prime}\left(d_{t+1}\right) \\
& z_{t+1}=\alpha w_{t+1}^{e} h\left(e_{t-1}\right) \gamma \ell\left(e_{t-1}\right) \\
& R_{t+1}^{e} R_{t}=\left[\begin{array}{c}
h^{\prime}\left(e_{t-1}\right)\left[\alpha^{2}\left(w_{t+1}^{e}\right)^{2} h\left(e_{t-1}\right) \gamma \ell\left(e_{t-1}\right)+R_{t+1}^{e} w_{t}\right] \\
+\ell^{\prime}\left(e_{t-1}\right)\left[d_{t+1}\left(\frac{1}{F^{R}}-1\right)-v_{\ell}\left(z_{t+1}, \ell\left(e_{t-1}\right)\right)\right]
\end{array}\right] \\
& L_{t}=h_{t}\left(e_{t-1}\right) N_{t}+z_{t} \alpha h_{t-1}\left(e_{t-2}\right) N_{t-1} \\
& K_{t}=N\left(s_{t-1}-e_{t-1}\right) \\
& w_{t}=F_{L}\left(K_{t}, L_{t}\right) \\
& R_{t}=F_{K}\left(K_{t}, L_{t}\right)
\end{aligned}
$$

If $\lim _{e_{t-1} \rightarrow 0} h^{\prime}\left(e_{t-1}\right)=+\infty, \lim _{e_{t-1} \rightarrow+\infty} h^{\prime}\left(e_{t-1}\right)=0, \lim _{e_{t-1} \rightarrow 0} \ell^{\prime}\left(e_{t-1}\right)=$ $+\infty$ and $\lim _{e_{t-1} \rightarrow+\infty} \ell^{\prime}\left(e_{t-1}\right)=0$, there exists an interior optimal level of $e_{t-1}$.

If $0<F^{R}<1$, and if $h(\cdot)$ and $\ell(\cdot)$ satisfy: $\left|h^{\prime \prime}\left(e_{t-1}\right)\right| h\left(e_{t-1}\right) \ell\left(e_{t-1}\right)>$ $\left(h^{\prime}\left(e_{t-1}\right)\right)^{2} \ell\left(e_{t-1}\right)+2 h^{\prime}\left(e_{t-1}\right) h\left(e_{t-1}\right) \ell^{\prime}\left(e_{t-1}\right)$, then the interior optimal level of $e_{t-1}$ is unique.

Proof. See the Appendix.

Note that, in comparison with Proposition 1, the uniqueness of an interior optimal level of education depends not only on the properties of the education return function $h(\cdot)$, but, also, on the shape of the longevity function $\ell(\cdot)$. In 
the exogenous case, we had $\ell^{\prime}\left(e_{t-1}\right)=0$, so that the above condition collapses to

$$
\frac{\left|h^{\prime \prime}\left(e_{t-1}\right)\right|}{h^{\prime}\left(e_{t-1}\right)}>\frac{h^{\prime}\left(e_{t-1}\right)}{h\left(e_{t-1}\right)}
$$

as in Proposition 1. However, in the endogenous case, $\ell^{\prime}\left(e_{t-1}\right)>0$ and thus the condition becomes also dependent on the shape of $\ell^{\prime}\left(e_{t-1}\right)$.

\section{Existence of a stationary equilibrium}

This section examines the conditions under which there exists a stationary equilibrium in our economy. For that purpose, we will, as above, distinguish between the two cases, where longevity is either exogenous or endogenous.

\subsection{Exogenous longevity}

To examine the existence of a stationary optimum under exogenous longevity, remind first that the problem of the individual is:

$\max _{e_{t-1}, s_{t}, z_{t+1}} u\left[w_{t} h\left(e_{t-1}\right)-e_{t-1} R_{t}-s_{t}\right]+\bar{\ell} u\left[\frac{z_{t+1} \alpha w_{t+1}^{e} h\left(e_{t-1}\right)-v\left(z_{t+1}, \bar{\ell}\right)+R_{t+1}^{e} s_{t}}{\bar{\ell}}\right]$

so that the FOCs yield, given $v\left(z_{t+1}, \bar{\ell}\right)=\frac{\left(z_{t+1}\right)^{2}}{2 \gamma \bar{\ell}}$ :

$$
\begin{aligned}
u^{\prime}\left(c_{t}\right) & =R_{t+1}^{e} u^{\prime}\left(d_{t+1}\right) \\
h^{\prime}\left(e_{t-1}\right)\left[\alpha^{2}\left(w_{t+1}^{e}\right)^{2} h\left(e_{t-1}\right) \gamma \bar{\ell}+R_{t+1}^{e} w_{t}\right] & =R_{t+1}^{e} R_{t}
\end{aligned}
$$

From the first FOC, we can rewrite optimal saving per young adult as a function of present and future factor prices, as well as the education level:

$$
s_{t} \equiv s\left(w_{t}, R_{t}, w_{t+1}^{e}, R_{t+1}^{e}, e_{t-1}\right)
$$

Indeed, given some values for parameters $\bar{\ell}, \alpha, \gamma$ and some functional forms for $u(\cdot)$ and $h(\cdot)$, saving depends only on education and present and expected future factor prices.

Regarding the education choice, we can, under the conditions for existence and uniqueness provided in Proposition 1, rewrite the optimal education as a function of present and future factor prices:

$$
e_{t-1} \equiv e\left(w_{t}, R_{t}, w_{t+1}^{e}, R_{t+1}^{e}\right)
$$

Indeed, given some values for parameters $\bar{\ell}, \alpha, \gamma$ and some functional forms for $u(\cdot)$ and $h(\cdot)$, the chosen level of education depends only on present and expected future factor prices. We also know from our conditions that this optimal education level is unique. 
Hence, given that the optimal education depends only on present and future factor prices, we can deduce that saving per young adult can be rewritten as:

$$
\begin{aligned}
s_{t} & \equiv s\left(w_{t}, R_{t}, w_{t+1}^{e}, R_{t+1}^{e}, e\left(w_{t}, R_{t}, w_{t+1}^{e}, R_{t+1}^{e}\right)\right) \\
& \equiv S\left(w_{t}, R_{t}, w_{t+1}^{e}, R_{t+1}^{e}\right)
\end{aligned}
$$

Given that factor prices obviously depend on the level of $k_{t}$, since $w_{t}=$ $f\left(k_{t}\right)-k_{t} f^{\prime}\left(k_{t}\right)$ and $R_{t}=f^{\prime}\left(k_{t}\right)$, the capital accumulation equation can be written in intensive terms (i.e. per effective unit of labor) as:

$$
k_{t+1}=\frac{S\left(w\left(k_{t}\right), R\left(k_{t}\right), w\left(k_{t+1}^{e}\right), R\left(k_{t+1}^{e}\right)\right)-e_{t}}{h\left(e_{t-1}\right)+z_{t} \alpha h\left(e_{t-2}\right)}
$$

Substituting for the optimal retirement age $\alpha w_{t} h\left(e_{t-2}\right) \gamma \bar{\ell}$ yields:

$$
k_{t+1}=\frac{S\left(w\left(k_{t}\right), R\left(k_{t}\right), w\left(k_{t+1}^{e}\right), R\left(k_{t+1}^{e}\right)\right)-e_{t}}{h\left(e_{t-1}\right)+\alpha^{2} w\left(k_{t}\right)\left[h\left(e_{t-2}\right)\right]^{2} \gamma \bar{\ell}}
$$

At the same time, education depends on present and future expected factor prices:

$$
e_{t-1} \equiv e\left(w\left(k_{t}\right), R\left(k_{t}\right), w\left(k_{t+1}^{e}\right), R\left(k_{t+1}^{e}\right)\right)
$$

We are thus in presence of a two dimensional system with three time lags.

Let us explore the conditions under which a stationary equilibrium with perfect foresight can exist. Under such an equilibrium, we have $k_{t+1}^{e}=k_{t+1}=$ $k_{t}=k$, and $e_{t}=e_{t-1}=e_{t-2}=e$, so that the pair $(e, k)$ must satisfy:

$$
\begin{aligned}
k & =\frac{S(w(k), R(k), w(k), R(k))-e}{h(e)+\alpha^{2} w(k)[h(e)]^{2} \gamma \bar{\ell}} \equiv \frac{\tilde{S}(k)-e}{h(e)+\alpha^{2} w(k)[h(e)]^{2} \gamma \bar{\ell}} \\
e & \equiv e(w(k), R(k), w(k), R(k)) \equiv \bar{e}(k)
\end{aligned}
$$

To examine the existence of such a pair, let us study some properties of those two relations. The following proposition summarizes our results.

Proposition 3 Suppose that the existence and uniqueness conditions of Proposition 1 hold. Denote the level of e satisfying $h(e)\left[1+\alpha^{2} w(k)[h(e)] \gamma \bar{\ell}\right]+\frac{e}{k}=$ $\frac{\tilde{S}(k)}{k}$ for a given $k$ by $\check{e}(k)$. Suppose that the level of $k>0$ such that $\check{e}(k)=0$ is unique. Suppose also that $\check{e}(k)$ is continuous in $k$, with $\check{e}^{\prime}(0)>\bar{e}^{\prime}(0)$ and $\check{e}(0) \geq 0$. Then a stationary equilibrium $\left(k^{E}, e^{E}\right)$ that satisfies (36) and (37) with $k^{E}>0$ exists.

Proof. See the Appendix.

Proposition 3 states conditions that are sufficient for existence of a stationary equilibrium with perfect foresight. It should be stressed that Proposition 3 relies on the conditions for a unique interior optimal education level stated in Proposition 1. Those conditions allow us to write education as a function $\bar{e}(k)$, which assigns to each level of $k$ a unique level for educational investment. In the 
Appendix we show that $\bar{e}^{\prime}(k)>0$ and $\bar{e}(0)=0$. For $\check{e}(k)$, see Figure 1. Figure 1.a illustrates the LHS of (36) (a 45 degree line) and the RHS of (36) with different levels of $e$. The dotted curve denotes the case when $e=0(h(e)=1)$. At $k=k^{a}>0$, the capital-market clears. In the figure there is another intersection at $k=0$ : this corresponds to an unstable steady-state in the OLG model. With higher levels of $e$, the curve that represents the RHS of (36) shifts down since the RHS of (36) is decreasing in $e$ (higher $e$ decreases the numerator ${ }^{4}$ and increases the denominator). Accordingly, the stable solution, starting from $k=k^{a}$, goes to the left; on the other hand, the unstable solution, starting from $k=0$, goes to the right. ${ }^{5}$ The curve in bold in Figure 1.a corresponds to the critical value of $e \equiv e^{b}$, above which the RHS does not have an intersection with the 45 degree line. In Figure 1.b, the solid downward curve is the stable solutions, and the dotted upward curve is the unstable solutions. They meet at $k=k^{b} \equiv \check{e}^{-1}\left(e^{b}\right) .^{6}$ The curve in bold in Figure 1.b is $\bar{e}(k)$ in equation (37). With the assumptions of the proposition the intersection of $\bar{e}(k)$ and $\check{e}(k)$ with $k>0$ exists.

Several remarks are in order. First, the intersection in Figure 1.b may be at the downward curve (stable solutions) or at the dotted upward curve (unstable solutions). Intuitively, if the "education demand" along $\bar{e}(k)$ cannot be afforded in the capital market along $k \in\left[k^{b}, k^{a}\right]$, then the intersection may be at the dotted curve. In either case, as in Phelps and Shell's (1969) growth model with the government's debt, the equilibrium level of $k$ could be higher or lower than that of the Modified Golden Rule that we introduce later in this paper. Second, note that Proposition 3 only informs us about the existence of a stationary equilibrium with perfect foresight, but does not inform us about the uniqueness. Uniqueness can only be examined provided particular functional forms are imposed for production, utility and education returns. The next subsection examines existence of a stationary equilibrium with perfect foresight once education increases longevity.

\footnotetext{
${ }^{4}$ In the Appendix we show that $s_{t}$ is decreasing in $e_{t}$ under exogenous longevity (equation $(84)$ in the proof of Proposition 2 when $\left.\ell^{\prime}(e)=0\right)$. This also reinforces the capital market tightening.

${ }^{5}$ This multiplicity of the capital-market equilibrium (with given $e$ ) is normal, and it is indeed very similar to Phelps and Shell (1969, Figure 2). The education investment $e$ here corresponds to the government's debt in Phelps and Shell (1969), and their "classical" and "anticlassical" ranges correspond to our stable and unstable solutions, respectively.

${ }^{6}$ In Figure 1.b, it is reasonable to assume continuity of the solid downward curve since all relevant functions are continuous and differentiable. Same for the dotted upward curve, and these two curves meet at $(k, e)=\left(k^{b}, e^{b}\right)$ at which the continuity is assured.
} 

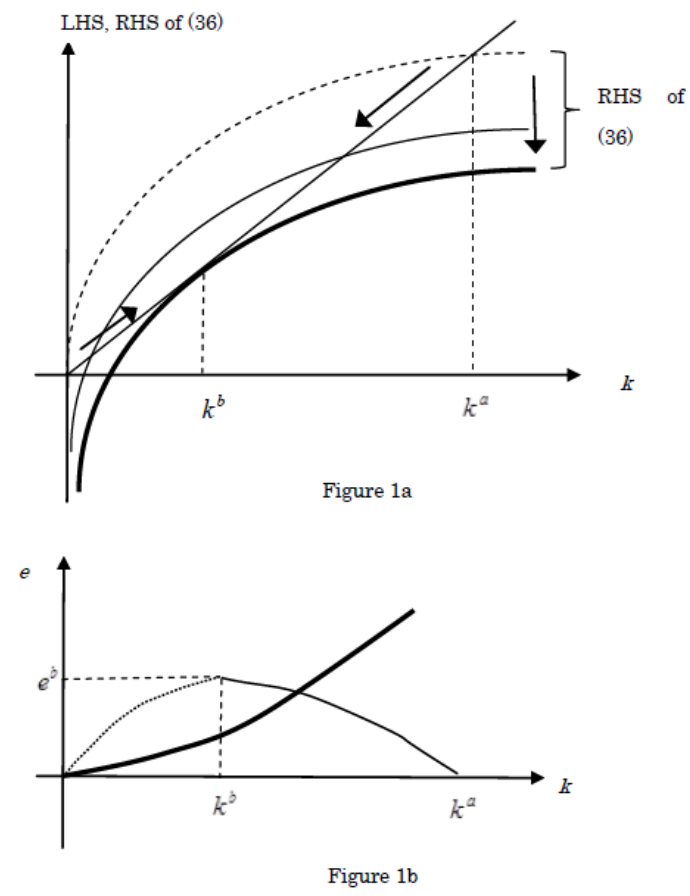

Figure 1: Existence of a stationary equilibrium.

\subsection{Endogenous longevity}

To examine the conditions under which a stationary equilibrium with perfect foresight exists, let us remind that the problem faced by the agent in the endogenous longevity case is:

$$
\max _{e_{t-1}, s_{t}, z_{t+1}}\left\{\begin{array}{l}
u\left[w_{t} h\left(e_{t-1}\right)-e_{t-1} R_{t}-s_{t}\right] \\
+\ell\left(e_{t-1}\right) u\left[\frac{z_{t+1} \alpha w_{t+1} h\left(e_{t-1}\right)-v\left(z_{t+1}, \ell\left(e_{t-1}\right)\right)+R_{t+1} s_{t}}{\ell\left(e_{t-1}\right)}\right]
\end{array}\right\}
$$

First-order conditions yield, under $v\left(z_{t+1}, \bar{\ell}\right)=\frac{\left(z_{t+1}\right)^{2}}{2 \gamma \ell\left(e_{t-1}\right)}$ :

$$
\begin{aligned}
u^{\prime}\left(c_{t}\right)= & R_{t+1} u^{\prime}\left(d_{t+1}\right) \\
R_{t+1}^{e} R_{t}= & h^{\prime}\left(e_{t-1}\right)\left[\alpha^{2}\left(w_{t+1}^{e}\right)^{2} h\left(e_{t-1}\right) \gamma \ell\left(e_{t-1}\right)+R_{t+1}^{e} w_{t}\right] \\
& +\frac{\ell^{\prime}\left(e_{t-1}\right)}{u^{\prime}\left(d_{t+1}\right)}\left[\begin{array}{c}
u\left(d_{t+1}\right)-u^{\prime}\left(d_{t+1}\right) d_{t+1} \\
-u^{\prime}\left(d_{t+1}\right) v_{\ell}\left(z_{t+1}, \ell\left(e_{t-1}\right)\right)
\end{array}\right]
\end{aligned}
$$

From the first FOC, we can, as above, rewrite optimal saving per young adult as a function of present and future factor prices, as well as the education 
level:

$$
s_{t} \equiv \hat{s}\left(w_{t}, R_{t}, w_{t+1}^{e}, R_{t+1}^{e}, e_{t-1}\right)
$$

Indeed, given some values for parameters $\alpha, \gamma$ and some functional forms for $u(\cdot)$ and $h(\cdot)$, saving depends only on education and present and expected future factor prices.

Regarding the education choice, we can, under the conditions for existence and uniqueness provided in Proposition 2, rewrite the optimal education as a function of present and future factor prices, as well as saving:

$$
e_{t-1} \equiv \hat{e}\left(w_{t}, R_{t}, w_{t+1}^{e}, R_{t+1}^{e}, s_{t}\right)
$$

Indeed, given some values for parameters $\alpha, \gamma$ and some functional forms for $u(\cdot)$ and $h(\cdot)$, the chosen level of education depends only on present and expected future factor prices, and on the saving level. We also know from our conditions that this optimal education level is unique. Given that $s_{t} \equiv \hat{s}\left(w_{t}, R_{t}, w_{t+1}^{e}, R_{t+1}^{e}, e_{t-1}\right)$, we can rewrite the education relation as:

$$
e_{t-1} \equiv \hat{e}\left(w_{t}, R_{t}, w_{t+1}^{e}, R_{t+1}^{e}, \hat{s}\left(w_{t}, R_{t}, w_{t+1}^{e}, R_{t+1}^{e}, e_{t-1}\right)\right)
$$

The capital accumulation equation can be written in intensive terms as:

$$
k_{t+1}=\frac{\hat{s}\left(w_{t}, R_{t}, w_{t+1}^{e}, R_{t+1}^{e}, e_{t-1}\right)-e_{t}}{h\left(e_{t-1}\right)+z_{t} \alpha h\left(e_{t-2}\right)}
$$

Substituting for the optimal retirement age $\alpha w_{t} h\left(e_{t-2}\right) \gamma \bar{\ell}$ yields:

$$
k_{t+1}=\frac{\hat{s}\left(w_{t}, R_{t}, w_{t+1}^{e}, R_{t+1}^{e}, e_{t-1}\right)-e_{t}}{h\left(e_{t-1}\right)+\alpha^{2} w\left(k_{t}\right)\left[h\left(e_{t-2}\right)\right]^{2} \gamma \ell(e)}
$$

At the same time, education depends on present and future expected factor prices and saving:

$$
e_{t-1}=\hat{e}\left(w_{t}, R_{t}, w_{t+1}^{e}, R_{t+1}^{e}, \hat{s}\left(w_{t}, R_{t}, w_{t+1}^{e}, R_{t+1}^{e}, e_{t-1}\right)\right)
$$

We are thus in presence of a two dimensional system with three time lags.

Let us explore the conditions under which a stationary equilibrium with perfect foresight can exist. Under such an equilibrium, we have $k_{t+1}^{e}=k_{t+1}=$ $k_{t}=k$, and $e_{t}=e_{t-1}=e_{t-2}=e$, so that we have:

$$
\begin{aligned}
k & =\frac{\hat{s}(w(k), R(k), w(k), R(k), e)-e}{h(e)+\alpha^{2} w(k)[h(e)]^{2} \gamma \ell(e)}=\frac{\tilde{s}(k, e)-e}{h(e)+\alpha^{2} w(k)[h(e)]^{2} \gamma \ell(e)} \\
e & =\hat{e}(w(k), R(k), w(k), R(k), \tilde{s}(k, e))=\tilde{e}(k, \tilde{s}(k, e))
\end{aligned}
$$

where $\tilde{s}(k, e) \equiv \hat{s}(w(k), R(k), w(k), R(k), e)$.

A stationary equilibrium with perfect foresight is a pair $(k, e)$ satisfying those two conditions. The following proposition summarizes our results. 
Proposition 4 Suppose that the existence and uniqueness conditions of Proposition 2 hold. Denote the level of e satisfying $e=\tilde{e}(k, \tilde{s}(k, e))$ for a given $k$ by $e=\bar{e}(k)$. Suppose that $\bar{e}(0)=0$ and $\bar{e}^{\prime}(k)>0$. Denote the level of e satisfying $h(e)\left[1+\alpha^{2} w(k) h(e) \gamma \ell(e)\right]+\frac{e}{k}=\frac{\tilde{s}(k, e)}{k}$ for a given $k$ by $e=\check{e}(k)$. Suppose that the level of $k>0$ such that $\check{e}(k)=0$ is unique. Suppose also that $\check{e}(k)$ is continuous in $k$, with $\check{e}^{\prime}(0)>\bar{e}^{\prime}(0)$ and $\check{e}(0) \geq 0$. Then a stationary equilibrium $\left(k^{E}, e^{E}\right)$ that satisfies (43) and (44) with $k^{E}>0$ exists.

Proof. See the Appendix.

Here again, it should be stressed, as in the case of Proposition 3, that the above conditions only guarantee that there exists at least one stationary equilibrium with perfect foresight, but do not exclude the possibility of several stationary equilibrium with perfect foresight. In order to study the uniqueness of that equilibrium, we would have to impose particular functional forms on the utility functions, the production functions, and on relations $h(e)$ and $\ell(e)$. Given that the emphasis of this paper lies on the Ben Porath effect, we will not carry out the discussion on the uniqueness of the stationary equilibrium here.

\section{The Ben-Porath effect reexamined}

Having shown that, under mild conditions, a stationary equilibrium with perfect foresight exists in our economy, we can now turn back to the study of the BenPorath effect. This section reexamines the conditions under which a rise in the lifetime horizon affects the education investment. For that purpose, we consider an economy at a stationary equilibrium with perfect foresight. Given that the Ben-Porath effect takes different forms when longevity is exogenous or when longevity depends on the education level, we will, here again, proceed in two cases, and consider first the case where longevity is exogenous, and, then, the case where longevity depends positively on education investment.

\subsection{Exogenous longevity}

In the case where longevity is purely exogenous, i.e. $\ell_{t}=\bar{\ell}$, the problem of agents can be written as: ${ }^{7}$

$$
\max _{e, s, z} u[w h(e)-e R-s]+\bar{\ell} u\left[\frac{z \alpha w h(e)-v(z, \bar{\ell})+R s}{\bar{\ell}}\right]
$$

First order conditions (FOCs) of this problem are:

$$
\begin{aligned}
& s \quad: \quad u^{\prime}(c)=R u^{\prime}(d) \\
& e: u^{\prime}(c)\left[w h^{\prime}(e)-R\right]+u^{\prime}(d) z \alpha w h^{\prime}(e)=0 \\
& z: \alpha w h(e)=v_{z}(z, \bar{\ell})=\frac{z}{\gamma \bar{\ell}}
\end{aligned}
$$

\footnotetext{
${ }^{7}$ We abstract here from time indices, since the economy is supposed to be at a stationary equilibrium.
} 
Using those conditions, we can, under exogenous longevity, characterize the stationary equilibrium with perfect foresight as follows.

Proposition 5 The stationary equilibrium under exogenous longevity is a vector $(e, c, s, d, z, w, R, K, L)$ satisfying the conditions:

$$
\begin{aligned}
c & =w h(e)-e R-s \\
d & =\frac{z \alpha w h(e)+R s-v(z, \bar{\ell})}{\bar{\ell}} \\
u^{\prime}(c) & =R u^{\prime}(d) \\
z & =\alpha w h(e) \gamma \bar{\ell} \\
h^{\prime}(e)\left[\alpha^{2}(w)^{2} h(e) \gamma \bar{\ell}+R w\right] & =R^{2} \\
L & =h(e) N+z \alpha h(e) N \\
K & =N(s-e) \\
w & =F_{L}(K, L) \\
R & =F_{K}(K, L)
\end{aligned}
$$

Proof. The proof follows immediately from the FOCs of agent and from firm's competitive behavior.

Let us use those FOCs to study the conditions under which the Ben Porath effect prevails in our economy.

Using the FOC for saving, the FOC for optimal education can be rewritten as:

$$
w h^{\prime}(e)[R+\alpha z]=R^{2}
$$

and, using the FOC for retirement,

$$
w h^{\prime}(e)\left[R+\alpha^{2} w h(e) \gamma \bar{\ell}\right]-R^{2}=\Delta
$$

In order to identify the effect of the life horizon on the education investment, we can compute:

$$
\frac{d e}{d \bar{\ell}}=\frac{\Delta_{\bar{\ell}}}{-\Delta_{e}}=\frac{h^{\prime}(e) \alpha^{2} w^{2} h(e) \gamma}{-\left[\alpha^{2} w^{2} \gamma \bar{\ell}\right]\left[h^{\prime \prime}(e) h(e)+\left[h^{\prime}(e)\right]^{2}\right]-h^{\prime \prime}(e) R w}
$$

where $\Delta_{e}<0$ because of the second-order condition.

In line with the literature on the Ben-Porath effect, one usually expects that a longer life horizon leads to a larger investment in education. Note, however, that, in our model, we have $\frac{d e}{d \bar{\ell}}=0$ when $\alpha=0$, that is, when there is a complete decay of human capital. Indeed, in that particular case, a rise in the duration of life does not favor more education, since at the old age the return of those educational investments are low because of the complete decay. Moreover, when $\gamma \rightarrow 0$, the marginal disutility of old age labor tends to be infinite, which implies that individuals retire at the beginning of the old age. Therefore, when $\gamma \rightarrow 0$, a rise in the time horizon has no impact on the optimal education, since 
those additional years will not be worked. The same result would hold in case of mandatory retirement at the beginning of the old age, implying $z=0$.

Hence our calculations seem to qualify the Ben Porath effect: the size of that effect depends on how large the decay of human capital is, and on how large the marginal disutility of old age labor is. The following proposition summarizes our results.

Proposition 6 Consider an economy with exogenous longevity at a stationary equilibrium with perfect foresight. The impact of life horizon on the education is given by:

$$
\frac{d e}{d \bar{\ell}}=\frac{h^{\prime}(e) \alpha^{2} w^{2} h(e) \gamma}{-\left[\alpha^{2} w^{2} \gamma \bar{\ell}\right]\left[h^{\prime \prime}(e) h(e)+\left[h^{\prime}(e)\right]^{2}\right]-h^{\prime \prime}(e) R w}
$$

The impact of life horizon on education is:

- increasing with the square of the wage rate $w$

- decreasing with the square of the human capital decay $1 / \alpha$

- decreasing with the strength of the marginal disutility of labor $1 / \gamma$

Proof. See above.

The above proposition shows that the size of the Ben-Porath effect depends, in our economy, on several forces, which affect the Ben-Porath effect in various ways. Some forces at work are related to preferences, such as the parameter $\gamma$ capturing the disutility of old age labor. Another important determinant, which is often neglected, consists of the extent of human capital decay $\alpha$. This affects the size of the Ben-Porath effect significantly. Indeed, the impact of a marginal change in $\bar{\ell}$ on education is proportional to the square of $\alpha$, which shows the significance of that parameter in the determination of the Ben-Porath effect. A simple corollary of the role of the decay is that, in societies with quicker technological progress, human capital's decay is stronger, implying, ceteris paribus, a reduction of the size of the Ben-Porath effect.

\subsection{Endogenous longevity}

Having studied the determinants of the Ben-Porath effect in the case of exogenous longevity, let us now consider the case where longevity is endogenous, and increasing in the amount of education investment. Under endogenous longevity, and still focusing on a stationary equilibrium with perfect foresight, the problem of the agent can be written as:

$$
\max _{e, s, z} u[w h(e)-e R-s]+\ell(e) u\left[\frac{z \alpha w h(e)-v(z, \ell(e))+R s}{\ell(e)}\right]
$$


First-order conditions are:

$$
\begin{array}{ll}
s: & u^{\prime}(c)=R u^{\prime}(d) \\
z & : \quad \alpha w h(e)=v_{z}(z, \ell(e)) \Longrightarrow z=\alpha w h(e) \gamma \ell(e) \\
e & : \quad u^{\prime}(c)\left[R-w h^{\prime}(e)\right]=u^{\prime}(d) z \alpha w h^{\prime}(e)+\ell^{\prime}(e)\left(\begin{array}{l}
u(d)-u^{\prime}(d) d \\
-u^{\prime}(d) v_{\ell}(z, \ell(e))
\end{array}\right)(53
\end{array}
$$

Using those conditions, we can characterize the stationary equilibrium with perfect foresight as follows.

Proposition 7 The stationary equilibrium under endogenous longevity is a vector $(e, c, s, d, z, w, R, K, L)$ satisfying the conditions:

$$
\begin{aligned}
c & =w h(e)-e R-s \\
d & =\frac{z \alpha w h(e)+R s-v(z, \ell(e))}{\ell(e)} \\
u^{\prime}(c) & =R u^{\prime}(d) \\
z & =\alpha w h(e) \gamma \ell(e) \\
R w h^{\prime}(e)+z \alpha w h^{\prime}(e)+\frac{\ell^{\prime}(e)}{u^{\prime}(d)}\left(\begin{array}{c}
u(d)-u^{\prime}(d) d \\
-u^{\prime}(d) v_{\ell}(z, \ell(e))
\end{array}\right) & =R^{2} \\
L & =h(e) N+z \alpha h(e) N \\
K & =N(s-e) \\
w & =F_{L}(K, L) \\
R & =F_{K}(K, L)
\end{aligned}
$$

Proof. The proof follows immediately from the FOCs of agent and from firm's competitive behavior.

Using the FOC for saving and the notation of the fear of ruin $F^{R} \equiv \frac{u^{\prime}(d) d}{u(d)}<$ 1, rewrite the FOC of education as:

$$
R^{2}=w h^{\prime}(e)[R+\alpha z]+\ell^{\prime}\left(e_{t-1}\right) d_{t+1}\left(\frac{1}{F^{R}}-1\right)-\ell^{\prime}\left(e_{t-1}\right) v_{\ell}\left(z_{t+1}, \ell\left(e_{t-1}\right)\right)
$$

In comparison with the case where longevity is exogenous, we have two additional terms on the RHS. The first additional term captures the pure effect of education on longevity, whereas the second additional term captures the effect of education on the disutility of old-age labor. Note that, since $v_{\ell}(z, \ell(e))<0$, that effect is positive: a higher investment in education tends, by reducing the disutility of old-age labor, to raise lifetime welfare.

Alternatively, that condition can be written as:

$$
R=w h^{\prime}(e)\left[1+\frac{\alpha z}{R}\right]+\frac{\ell^{\prime}(e) d_{t+1}}{R}\left(\frac{1}{F^{R}}-1\right)-\frac{\ell^{\prime}(e) v_{\ell}(z, \ell(e))}{R}
$$

Hence, at the equilibrium, the marginal cost of education $R$ must be equal to the marginal benefits from education, which are composed of three terms: 
(1) its pure return on labor earnings; (2) its effect on longevity; (3) its positive effect on the disutility of old-age labor.

As we did in the case of exogenous longevity, we can now consider whether the Ben-Porath effect remains true in our framework. For that purpose, we consider now a displacement of the function $\ell(e)$. Let us now define $\tilde{\ell}(e)=$ $\lambda \ell(e)$.

As in (49),

$$
w h^{\prime}(e)[R+\alpha z]+\lambda \ell^{\prime}\left(e_{t-1}\right)\left[d_{t+1}\left(\frac{1}{F^{R}}-1\right)-v_{\ell}\left(z_{t+1}, \lambda \ell\left(e_{t-1}\right)\right)\right]=\Delta
$$

We want to know the value of

$$
\frac{d e}{d \lambda}=\frac{\Delta_{\lambda}}{-\Delta_{e}},
$$

where $\Delta_{e}<0$ from the second-order condition. In the Appendix we show that

$$
\frac{d e}{d \lambda}=\frac{h^{\prime}(e) w^{2} \alpha^{2} h(e) \gamma \ell(e)-\ell^{\prime}(e) v_{\ell}(z, \lambda \ell(e))+\ell^{\prime}(e)\left(\frac{1}{F^{R}}-1\right)\left(d+\lambda \frac{\partial d}{\partial \lambda}\right)}{-\Delta_{e}}
$$

That formula is more complex than in the case of exogenous longevity. However, it is easy to see that, when $\ell^{\prime}(e)$ tends towards 0 , that expression vanishes to the one prevailing in the case of exogenous longevity. In comparison with that formula, two additional terms are present.

The term $-\ell^{\prime}(e) v_{\ell}(z, \lambda \ell(e))$ reflects the fact that an improvement of longevity, by reducing the extent of disutility of old-age labor, tends to make a larger investment in education more desirable. Hence, ceteris paribus, this effect pushes towards a higher investment in education. The extent of that effect depends on the marginal effect of a rise in education on longevity, as well as on the form of the disutility of old age labor function $v(z, \lambda \ell(e))$.

The term $\ell^{\prime}(e)\left(\frac{1}{F^{R}}-1\right)\left(d+\lambda \frac{\partial d}{\partial \lambda}\right)$ reflects the effect of a favorable displacement of the function $\ell(e)$ on longevity. Note that there is an effect of increasing $\lambda$ on the second-period consumption, $\frac{\partial d}{\partial \lambda}$. In the Appendix we show that $\frac{\partial d}{\partial \lambda}<0$. Intuitively, an increase in longevity has a depressive effect on the flow of consumption in the second period. This can be called a dilution effect. However, in the Appendix we show that $d+\frac{\partial d}{\partial \lambda}>0$ : the overall effect is unambiguously positive, so that this term also makes a larger investment in education more desirable. Note also that this additional effect depends on the degree of fear of ruin $F^{R}$. The higher $F^{R}$ is, the lower this additional effect is.

It is worthy to note that, even when there is complete decay of human capital (i.e. $\alpha=0$ ), or even when $z=0$, an increase in $\lambda$ tends unambiguously to boost education.

The following proposition summarizes our results. 
Proposition 8 Consider an economy with endogenous longevity at its stationary equilibrium with perfect foresight. Let us define $\tilde{\ell}(e)=\lambda \ell(e)$ and consider the impact of a displacement of the function $\tilde{\ell}(e)$ by a change of $\lambda$. The impact of that displacement on the education is given by:

$\frac{d e}{d \lambda}=\frac{h^{\prime}(e) w^{2} \alpha^{2} h(e) \gamma \ell(e)-\ell^{\prime}(e) v_{\ell}(z, \lambda \ell(e))+\ell^{\prime}(e)\left(\frac{1}{F^{R}}-1\right)\left(d+\lambda \frac{\partial d}{\partial \lambda}\right)}{-\Delta_{e}}>0$.

Proof. See the Appendix.

The determinants of the size of the Ben-Porath effect are, in the case of endogenous longevity, more numerous than in the case of exogenous longevity. Quite importantly, due to the presence of the three additional effects mentioned above, the size of the Ben-Porath effect depends now on the extent to which better survival conditions reinforce the marginal welfare gains, in terms of a longer life, from education investment, as well as on the extent to which education will contribute to allow individuals to work longer, thanks to a better health. The size of those three effects depends crucially on the shape of individual preferences, in particular the degree of fear of ruin, a factor that was absent in the case of exogenous longevity.

\section{The social optimum}

So far, we only considered the Ben-Porath effect from a purely positive perspective. Our explorations allowed us to identify the conditions under which the Ben-Porath effect is more or less sizeable, in terms of the structural parameters of the economy. Besides those positive issues, another important question concerns the definition of the optimal public policy in an economy characterized by some form of Ben-Porath effect. The question at stake is thus: how should governments intervene in a Ben-Porath economy? To answer that question, a first, necessary stage consists in characterizing the social optimum.

For that purpose, let us consider the following social planning problem. The social planner chooses consumptions, education, retirement age and physical capital in such a way as to maximize the sum of generational lifetime welfare levels, subject to the resource constraint of the economy. ${ }^{8}$ That problem can be written as:

$$
\max _{c_{t}, d_{t}, e_{t}, z_{t}, k_{t}} \sum\left\{\begin{array}{l}
\beta^{t}\left[u\left(c_{t}\right)+\ell_{t+1}\left(e_{t-1}\right) u\left(d_{t+1}\right)\right] \\
-\mu_{t}\left[\begin{array}{l}
c_{t}+\ell_{t}\left(e_{t-2}\right) d_{t}+e_{t}+\tilde{k}_{t+1}+v\left(z_{t}, \ell_{t}\left(e_{t-2}\right)\right) \\
-F\left(\tilde{k}_{t}, h\left(e_{t-1}\right)+\alpha z_{t} h\left(e_{t-2}\right)\right)
\end{array}\right]
\end{array}\right\}
$$

\footnotetext{
${ }^{8}$ In so doing, we deliberately neglect the objection that the utilitarian approach with variable longevity implies a bias towards the long-lived individuals. On this, see Pestieau and Ponthiere (2015).
} 
The FOCs of that social planning problem are:

$$
\begin{aligned}
c_{t}: & \beta^{t} u^{\prime}\left(c_{t}\right)=\mu_{t} \\
d_{t}: & \beta^{t-1} u^{\prime}\left(d_{t}\right)=\mu_{t} \\
k_{t}: & \mu_{t} F_{\tilde{k}_{t}}(\cdot)=\mu_{t-1} \\
z_{t}: & v_{z_{t}}\left(z_{t}, \ell\left(e_{t-2}\right)\right)=F_{L_{t}}(\cdot) \alpha h\left(e_{t-2}\right) \\
e_{t}: & \beta^{t+1} \frac{\partial \ell_{t+2}}{\partial e_{t}} u\left(d_{t+2}\right)-\mu_{t+2} \frac{\partial \ell_{t+2}}{\partial e_{t}} d_{t+2}-\mu_{t}-\mu_{t+2} v_{\ell_{t+2}}(\cdot) \frac{\partial \ell_{t+2}}{\partial e_{t}} \\
& +\mu_{t+1} F_{L_{t+1}}(\cdot) h^{\prime}\left(e_{t}\right)+\mu_{t+2} F_{L_{t+2}}(\cdot) \alpha z_{t+2} h^{\prime}\left(e_{t}\right) \\
= & 0
\end{aligned}
$$

Focusing on a stationary state in which $\mu_{t}=\beta \mu_{t-1}$, we have:

$$
\beta^{-1}=F_{L}(\cdot) h^{\prime}(e)(1+\alpha z \beta)+\frac{\partial \ell}{\partial e} \beta\left[d\left(\frac{1}{F^{R}}-1\right)-v_{\ell}(z, \ell(e))\right]
$$

Let $F_{L}(\cdot)=w$ and $\beta^{-1}=F_{\tilde{k}}(\cdot)=R$. We then obtain:

$$
R^{2}=w h^{\prime}(e)(R+\alpha z)+\frac{\partial \ell}{\partial e}\left[d\left(\frac{1}{F^{R}}-1\right)-v_{\ell}(z, \ell(e))\right]
$$

Comparing that expression with the FOC for optimal education at the laissez-faire, that is,

$$
R^{2}=w h^{\prime}(e)[R+\alpha z]+\ell^{\prime}\left[d\left(\frac{1}{F^{R}}-1\right)-v_{\ell}(z, \ell(e))\right]
$$

we can see that the social optimum can be decentralized provided the laissezfaire capital stock corresponds to the one satisfying the Modified Golden Rule:

$$
\frac{\partial F\left(\tilde{k}^{*},(1+\alpha z) h\right)}{\partial \tilde{k}}=\frac{1}{\beta}
$$

Hence, the social optimum can be decentralized by merely decentralizing the capital stock satisfying the Modified Golden Rule. As soon as the capital stock takes that level, then all the other variables, such as consumptions, education, and retirement age, take their socially optimal levels. In order to understand that result, let us remind that individual education choices at the laissez-faire do not suffer from particular imperfections at the level of markets or of individual rationality (myopia, etc.). The only reason why the amount of education chosen by individuals at the laissez-faire is not socially optimal is due to the fact that, when the economy is in underaccumulation of capital, the cost of funding of education is too large in comparison to what would be socially optimal, and, as a consequence, the chosen education level is too low in comparison with what prevails at the social optimum. As a consequence, once the capital stock takes its Modified Golden Rule level, it follows that the interest factor $R$ is lower, which leads to a higher amount of education.

The following proposition summarizes our results. 
Proposition 9 The long-run social optimum is a vector $(c, d, z, e, k, w, R)$ satisfying the conditions:

$$
\begin{aligned}
u^{\prime}(c) & =u^{\prime}(d) \beta^{-1} \\
F_{\tilde{k}}(\cdot) & =\beta^{-1}=R \\
F_{L}(\cdot) & =w \\
v_{z}(z, \ell(e)) & =F_{L}(\cdot) \alpha h(e) \\
R^{2} & =w h^{\prime}(e)(R+\alpha z)+\frac{\partial \ell}{\partial e}\left[d\left(\frac{1}{F^{R}}-1\right)-v_{\ell}(z, \ell(e))\right] \\
c+\ell(e) d+e+\tilde{k}+v(z, \ell(e)) & =F(\tilde{k}, h(e)+\alpha z h(e))
\end{aligned}
$$

The long-run social optimum can be decentralized by means of a system of intergenerational lumpsum transfers leading to the Modified Golden Rule capital level.

Proof. See above.

\section{Optimal second-best policy}

Up to now, we considered an economy composed of identical individuals. Let us now consider an economy where individuals differ regarding their ability to transform educational investment into human capital. That source of heterogeneity can be regarded as individual differences in their learning ability. We suppose two types of individuals, differing regarding their learning ability $a_{i}$. Type-1 agent exhibits a lower ability to learn than type- 2 agent:

$$
a_{2}>a_{1}
$$

In order to model this difference, we will now suppose that labor income for an individual of type $i \in\{1,2\}$ is linear in the learning ability and in the education level:

$$
y_{i}=a_{i} e_{i}
$$

For the sake of simplicity, we now abstract from the retirement decision, and suppose that the hourly wage and the interest factor are both equal to 1 : $w=R=1$.

Let us first look at the laissez-faire outcome. Denoting the maximum utility level attainable at the laissez-faire allocation as a function of individual ability $a_{i}$,

$$
U\left(a_{i}\right) \equiv \max _{e_{i}, s_{i}} u\left[a_{i} e_{i}-e_{i}-s_{i}\right]+\ell\left(e_{i}\right) u\left(\frac{s_{i}}{\ell\left(e_{i}\right)}\right) .
$$

The FOCs are:

$$
\begin{array}{lll}
s_{i}: & u^{\prime}\left(c_{i}\right)=u^{\prime}\left(d_{i}\right) \\
e_{i}: & u^{\prime}\left(c_{i}\right)\left[a_{i}-1\right]+\ell^{\prime}\left(e_{i}\right)\left(u\left(d_{i}\right)-d_{i} u^{\prime}\left(d_{i}\right)\right)=0
\end{array}
$$


By the envelope theorem,

$$
\frac{\partial U\left(a_{i}\right)}{\partial a_{i}}=e_{i}^{*} u_{i}^{* \prime}>0 .
$$

Therefore, type 2 ends up with higher utility than type 1 . As in the conventional scenario, the utilitarian social planner aims at redistributing income from type 2 to type 1.

In the rest of this section, we first characterize the social optimum, under the assumption that the learning ability of individuals cannot be easily observed by the social planner. Given the asymmetric information on the learning ability, we consider now a second-best social optimum. Then, we will derive the associated second-best optimal non linear taxation scheme.

The second-best social planning problem consists in deriving, for each types $i \in\{1,2\}$, baskets $\left\{x_{i}, y_{i}, s_{i}\right\}$ that maximize social welfare, subject to the resource constraint of the economy, and subject to incentive constraints. ${ }^{9}$ That planning problem can be written by means of the following Lagrangian:

$$
\mathcal{L}=\sum_{i=1,2}\left\{\begin{array}{c}
u\left(x_{i}-\frac{y_{i}}{a_{i}}-s_{i}\right)+\ell\left(\frac{y_{i}}{a_{i}}\right) u\left(\frac{s_{i}}{\ell\left(\frac{y_{i}}{a_{i}}\right)}\right)+\mu\left(y_{i}-x_{i}\right) \\
+\lambda\left[\begin{array}{c}
u\left(x_{2}-\frac{y_{2}}{a_{2}}-s_{2}\right)+\ell\left(\frac{y_{2}}{a_{2}}\right) u\left(\frac{s_{2}}{\ell\left(\frac{y_{2}}{a_{2}}\right)}\right) \\
-u\left(x_{1}-\frac{y_{1}}{a_{2}}-s_{1}\right)-\ell\left(\frac{y_{1}}{a_{2}}\right) u\left(\frac{s_{1}}{\ell\left(\frac{y_{1}}{a_{2}}\right)}\right)
\end{array}\right]
\end{array}\right\}
$$

where $\mu$ is the Lagrange multiplier associated to the resource constraint for each type, while $\lambda$ is the Lagrange multiplier associated with the incentive compatibility constraint. That constraint guarantees that individuals with a high learning ability will not be interested in pretending to have a low learning ability.

The FOCs for optimal $x_{1}$ and $x_{2}$ are:

$$
\begin{aligned}
& x_{1} \quad: \quad u^{\prime}\left(c_{1}\right)=\mu+\lambda u^{\prime}\left(\tilde{c}_{2}\right) \\
& x_{2} \quad: \quad(1+\lambda) u^{\prime}\left(c_{2}\right)=\mu
\end{aligned}
$$

where $\tilde{c}_{2} \equiv x_{1}-\frac{y_{1}}{a_{2}}-s_{1}$.

The FOCs for optimal $s_{1}$ and $s_{2}$, taking account of (67), are:

$$
\begin{aligned}
s_{1} \quad: \quad-u^{\prime}\left(c_{1}\right)+u^{\prime}\left(d_{1}\right)+\lambda\left[u^{\prime}\left(\tilde{c}_{2}\right)-u^{\prime}\left(\tilde{d}_{2}\right)\right]=0 \\
\quad \Longrightarrow \quad u^{\prime}\left(d_{1}\right)=\mu+\lambda u^{\prime}\left(\tilde{d}_{2}\right) \\
s_{2} \quad: \quad(1+\lambda)\left[-u^{\prime}\left(c_{2}\right)+u^{\prime}\left(d_{1}\right)\right]=0 \quad \Longrightarrow \quad u^{\prime}\left(d_{2}\right)=u^{\prime}\left(c_{2}\right)
\end{aligned}
$$

Equation (70) shows that the Euler equation of intertemporal consumption holds for type 2 .

\footnotetext{
${ }^{9} \mathrm{We}$ assume that $s_{i}$ is observable and can be subject to a non-linear tax scheme.
} 
On the other hand, for type 1's intertemporal consumption, $c_{1}<\tilde{c}_{2}$ and (67) together imply $(1-\lambda) u^{\prime}\left(c_{1}\right)<\mu$. Also, $\frac{y_{1}}{a_{1}}<\frac{y_{1}}{a_{2}}$ implies $d_{1}>\tilde{d}_{2}$, so (69) implies $(1-\lambda) u^{\prime}\left(d_{1}\right)>\mu$. Therefore:

$$
u^{\prime}\left(c_{1}\right)<u^{\prime}\left(d_{1}\right)
$$

Hence we have:

$$
(1+\eta) u^{\prime}\left(c_{1}\right)=u^{\prime}\left(d_{1}\right)
$$

where $\eta>0$. Thus the second-best optimum involves a downward distortion on the saving of type- 1 individuals, that is, of individuals with the low learning ability.

The FOCs for optimal $y_{1}$ and $y_{2}$ are:

$$
\begin{aligned}
\frac{-\left[u^{\prime}\left(c_{1}\right)-\ell^{\prime}\left(e_{1}\right) \Omega\left(d_{1}\right)\right]}{a_{1}}+\mu+\lambda \frac{\left[u^{\prime}\left(\tilde{c}_{2}\right)-\ell^{\prime}\left(\frac{y_{1}}{a_{2}}\right) \Omega\left(\tilde{d}_{2}\right)\right]}{a_{2}} & =0 \\
-\frac{(1+\lambda)\left[u^{\prime}\left(c_{2}\right)-\ell^{\prime}\left(e_{2}\right) \Omega\left(d_{2}\right)\right]}{a_{2}}+\mu & =0
\end{aligned}
$$

where $\Omega\left(d_{i}\right) \equiv u\left(d_{i}\right)-d_{i} u^{\prime}\left(d_{i}\right)$.

Given $(1+\lambda) u^{\prime}\left(c_{2}\right)=\mu$, the FOC for $y_{2}$ can be written as:

$$
\frac{1}{a_{2}}\left[1-\ell^{\prime}\left(e_{2}\right) \frac{\Omega\left(d_{2}\right)}{u^{\prime}\left(c_{2}\right)}\right]=1
$$

Moreover, given that $u^{\prime}\left(c_{1}\right)=\mu+\lambda u^{\prime}\left(\tilde{c}_{2}\right)$ and the FOC for $y_{1}$, we obtain that:

$$
\left[-1+\ell^{\prime}\left(e_{1}\right) \frac{\Omega\left(d_{1}\right)}{u^{\prime}\left(c_{1}\right)}\right] \frac{\left[1+\frac{\lambda}{\mu} u^{\prime}\left(\tilde{c}_{2}\right)\right]}{a_{1}}+1+\frac{\frac{\lambda}{\mu} u^{\prime}\left(\tilde{c}_{2}\right)}{a_{2}}\left[1-\ell^{\prime}\left(\frac{y_{1}}{a_{2}}\right) \frac{\Omega\left(\tilde{d}_{2}\right)}{u^{\prime}\left(\tilde{c}_{2}\right)}\right]=0
$$

Using those FOCs, it can be shown that, when individuals differ in their learning ability, the non linear tax scheme implies a downward distortion on the level of education of the less able type, and, henceforth, increases the longevity gap between the two types.

To show this, let us denote the marginal rate of substitution MRS for type 1 and type 2 (the mimicker) by, respectively $A_{1}$ and $\tilde{A}_{2}$, where:

$$
\begin{aligned}
& A_{1} \equiv\left[1-\frac{\ell^{\prime}\left(e_{1}\right) \Omega\left(d_{1}\right)}{u^{\prime}\left(c_{1}\right)}\right] \frac{1}{a_{1}} \\
& \tilde{A}_{2} \equiv\left[1-\frac{\ell^{\prime}\left(\tilde{e}_{2}\right) \Omega\left(\tilde{d}_{2}\right)}{u^{\prime}\left(\tilde{c}_{2}\right)}\right] \frac{1}{a_{2}}
\end{aligned}
$$

By assuming that the single crossing property holds, it must be the case that $\tilde{A}_{2}<A_{1}$. 
Using the FOCs, we obtain:

$$
1-A_{1}=\frac{\lambda}{\mu} u^{\prime}\left(\tilde{c}_{2}\right)\left[A_{1}-\tilde{A}_{2}\right]
$$

It follows that $A_{1}<1$. Using the definition of $A_{1}$, this implies that:

$$
\left[1-\frac{\ell^{\prime}\left(e_{1}\right) \Omega\left(d_{1}\right)}{u^{\prime}\left(c_{1}\right)}\right]<a_{1}
$$

Hence it follows that

$$
a_{1}+\frac{\ell^{\prime}\left(e_{1}\right) \Omega\left(d_{1}\right)}{u^{\prime}\left(c_{1}\right)}=1+\theta
$$

where $\theta>0$. Thus the second-best optimum involves a downward distortion on the education of type- 1 individuals, that is, of individuals with the low learning ability.

In the light of this, the decentralization of the second-best social optimum requires a $\operatorname{tax} T_{a}$ on the effective unit of education effort $\left(y_{1}\right)$ and a $\operatorname{tax} T_{b}$ on saving of the individuals with low learning ability. Under such taxes, the problem for type-1 individuals becomes:

$$
\max _{y_{1}, s_{1}} u\left[y_{1}-\frac{y_{1}}{a_{1}}-T_{a}\left(y_{1}\right)-s_{1}-T_{b}\left(s_{1}\right)\right]+\ell\left(\frac{y_{1}}{a_{1}}\right) u\left(\frac{s_{1}}{\ell\left(\frac{y_{1}}{a_{1}}\right)}\right)
$$

The FOCs are:

$$
\begin{aligned}
& s_{1}: \quad\left(1+T_{b}^{\prime}\left(s_{1}\right)\right) u^{\prime}\left(c_{1}\right)=u^{\prime}\left(d_{1}\right) \\
& y_{1}: u^{\prime}\left(c_{1}\right)\left[1-\frac{1}{a_{1}}-T_{a}^{\prime}\left(y_{1}\right)\right]+\frac{1}{a_{1}} \ell^{\prime}\left(\frac{y_{1}}{a_{1}}\right)\left(u\left(d_{1}\right)-d_{1} u^{\prime}\left(d_{1}\right)\right)=0
\end{aligned}
$$

From the last FOC, we obtain:

$$
\frac{u^{\prime}\left(d_{1}\right)}{u^{\prime}\left(c_{1}\right)}=1+T_{b}^{\prime}\left(s_{1}\right), a_{1}+\ell^{\prime}\left(e_{1}\right) \frac{\Omega\left(d_{1}\right)}{u^{\prime}\left(c_{1}\right)}=1+T_{a}^{\prime}\left(y_{1}\right) \cdot a_{1}
$$

which, by setting $T_{a}^{\prime}\left(y_{1}\right)=\theta / a_{1}$ and $T_{b}^{\prime}\left(s_{1}\right)=\eta$, coincides with the condition of the optimal level of $s_{1}$ and $e_{1}$ at the second-best.

The intuition behind this second-best argument for taxing the education of individuals with low learning ability goes as follows. Given the asymmetry of information, it is tempting for high learning ability types to pretend to have a low learning ability, in such a way as to benefit from redistribution. The introduction of an incentive compatibility constraint allows the government to avoid that mimicking. However, avoiding this mimicking has a cost. The only way to discourage the mimicking of the high learning ability individuals consists in taxing the education of those who claim to have low learning ability. By doing so, the government annihilates the incentives of high learning ability individuals to pretend to be a low learning ability type. Indeed, high learning 
ability individuals are those who most value education investment. Taxing the good they consume most suffices thus to provide them the incentives to claim to have high learning ability, because they would not gain, under that tax, to pretend from having a low learning ability. The intuition behind the saving taxation is simple. Given that the mimickers live longer than true type 1, taxing their second-period consumption (again, the good preferred by the mimicker) discourages their incentives to claim to have low learning ability.

The following proposition summarizes our results.

Proposition 10 Consider an economy with two types of individuals, differing in their learning ability.

Under asymmetric information, the optimal non linear tax scheme implies a downward distortion on the level of education and saving of the less able type.

This downward distortion contributes to increase the gaps on longevity and saving between the two types.

Proof. See above.

The second part of that proposition is counterintuitive: the second-best optimal policy involves to raise the longevity gap between the two types of agents, which seems paradoxical. However, this surprising fact follows from the postulated relation between education and longevity. Given that relation, it is impossible to distort the education of the low ability type downwards without also reducing their longevity, which contributes to raise longevity inequalities between types.

\section{Concluding remarks}

In the recent years, a large attention was paid to the study of the Ben-Porath effect, according to which a rise in life expectancy will, by increasing the lifetime return of education, contribute to encourage education. The present paper proposed to reexamine the Ben-Porath effect in an OLG economy where individuals choose their education, their saving and when they retire, and where education investments do not only raise future wages - possibly with some decay - but contribute also to raise longevity.

Our main results are the following. First, we emphasized that the BenPorath effect varies strongly depending on whether we consider an economy with exogenous or with endogenous longevity. This fact could have been guessed

from the literature, but this paper proposes a comparison of those two kinds of Ben-Porath effects within the same theoretical setting. This comparison allowed us to highlight that, in both cases, the strength of the Ben-Porath effect depends on the future wages, the marginal return of education, the strength of the decay in human capital, as well as on the marginal disutility of old-age labor.

That comparison emphasized also some differences: once the feedback effect is introduced (i.e. endogenous longevity), the size of the Ben-Porath effect depends on a particular aspect of preferences - the fear of ruin - which does not enter the Ben Porath effect under exogenous longevity. Individual heterogeneity 
in their attitude towards risk may thus explain part of the mixed results concerning the empirical validation of the Ben Porath effect. The comparison also highlighted the presence of an additional effect under endogenous longevity: the fact that a rise in life expectancy may also reduce the disutility of old age labor, which, in turn, may increase even more the rise in education returns obtained through the increase in life expectancy.

On the normative side, our analyses highlighted that the long-run social optimum can be decentralized, within our economy, by merely decentralizing the Modified Golden Rule capital level. Such a decentralization, by reducing the interest rate, will also reduce the cost of education funding, and, hence, will induce the socially optimal level of education. We also considered a modified framework with heterogeneity on learning ability, and we showed that it is optimal, under asymmetric information on learning ability, to distort downwards the education of the low ability type, which will deter high ability types from mimicking low ability type, but at the cost of raising the longevity gap between the two types of individuals.

\section{References}

Acemoglu, D., Johnson, S., 2007, "Disease and Development: the Effect of Life Expectancy on Economic Growth", Journal of Political Economy, 115(6), 925-985.

Barro, R., Becker, G., 1989, "Fertility Choice in a Model of Economic Growth", Econometrica, 57(2), 481-501.

Ben Porath, Y., 1967, "The Production of Human Capital and the Life-cycle of Earnings", Journal of Political Economy, 75(3), 352-365.

Blackburn, K., Cipriani, J.P., 2002, "A Model of Longevity, Fertility and Growth", Journal of Economic Dynamics and Control, 26, 187-204.

Bloom, D., Canning, D., Fink, G., 2014. "Disease and Development Revisited", Journal of Political Economy, 122(6): 1355 - 1366.

Bloom, D., Canning, D., Sevilla, J., 2004. "The Effect of Health on Economic Growth: A Production Function Approach," World Development, 32(1), 1-13.

Bloom, D., Sachs, J., 1998. "Geography, Demography, and Economic Growth in Africa", Brookings Papers in Economic Activity, 2, 207-273.

Bloom, D., Williamson, J.G., 1998. "Demographic Transitions and Economic Miracles in Emerging Asia", World Bank Economic Review, 12 (3), 419-455.

Bommier, A., 2007. "Risk Aversion, Intertemporal Elasticity of Substitution and Correlation Aversion", Economics Bulletin, 29: 1-8.

Boucekkine, R., de la Croix, D., Licandro, O., 2002, "Vintage Human Capital, Demographic Trends and Endogenous Growth", Journal of Economic Theory, 104(2), 340-375.

Cervellati, M., Sunde, U., 2005, "Human Capital Formation, Life Expectancy and the Process of Development",American Economic Review, 95(5), 1653-1672.

Cervellati, M., Sunde, U., 2011, "Life Expectancy and Economic Growth: The Role of the Demographic Transition", Journal of Economic Growth, 16(2), 99-133.

Chakraborty, S., 2004, "Endogenous Lifetime and Economic Growth", Journal of Economic Theory, 116(1), 119-137. 
de la Croix, D., Licandro, O., 2013, "'The Child is Father of the Man:' Implications for the Demographic Transition", Economic Journal, 123, 236-261.

de la Croix, D., Lindh, T., Malmberg, B., 2009, "Demographic Change and Economic Growth in Sweden: 1750-2050," Journal of Macroeconomics, 31(1), 132-148.

Deboosere, P, Gadeyne, S. \& Van Oyen H (2009): "The 1991-2004 Evolution in Life Expectancy by Educational Level in Belgium Based on Linked Census and Population Register Data", European Journal of Population, 25, 175-196.

Eeckhoudt, L, Pestieau, P., 2008, "A Note on Longevity Enhancing Investment", Economics Letters, 101, 57-59.

Ehrlich, I., Lui, F., 1991, "Intergenerational Trade, Longevity, and Economic Growth", Journal of Political Economy, 99(5), 1029-59.

Galor, O., Moav, O., 2002. "Natural Selection and the Origin of Economic Growth", Quarterly Journal of Economics, 117 (4), 1133-1191.

Galor, O., Moav, O., 2005. "Natural Selection and the Evolution of Life Expectancy", CEPR, Minerva Center for Economic Growth Paper 02-05.

Gallup, J., Sachs, J., 2001. "The Economic Burden of Malaria", American Journal of Tropical Medicine and Hygiène, 64 (1), 85-96.

Hazan, M., 2009. "Longevity and Lifetime Labor Supply: Evidence and Implications," Econometrica, 77(6), 1829-1863.

Kremer, M. 1993. "Population Growth and Technological Change: One Million B.C. to 1990", The Quarterly Journal of Economics, 108(3), 681-716.

Leker, L., Ponthiere, G., 2015. "Education, Life Expectancy and Family Bargaining: the Ben-Porath Effect Revisited", Education Economics, 23 (4) 481-513.

Ludwig, A., Vogel, E., 2010. "Mortality, Fertility, Education and Capital Accumulation in a Simple OLG Economy", Journal of Population Economics, 23, 703-735.

Pestieau, P., Ponthiere, G., 2015. "Longevity Variations and the Welfare State", CORE Discussion Paper 2015-27.

Phelps, E., Shell, K., 1969. "Public Debt, Taxation, and Capital Intensiveness," Journal of Economic Theory, 1 (3), 330-346.

Romer, P. M., 1990, "Endogenous Technological Change", Journal of Political Economy, vol 98 (5), S71-102.

Samuelson, P., 1975. "The Optimum Growth Rate for Population". International Economic Review, 16 (3), 531-538.

Soares, R., 2005, "Mortality Reductions, Educational Attainment and Fertility choice", The American Economic Review, vol. 95(3), 580-601.

Solow, R., 1956. "A Contribution to the Theory of Economic Growth", Quarterly Journal of Economics, 70 (1), 65-94.

\section{Appendix}

\subsection{Proof of Proposition 1}

The first part of the proposition follows from the FOCs and the conditions for profit maximization of firms in a competitive economy. The second part of the proposition can be proved as follows. 
Suppose $e_{t-1}=0$. Then the marginal welfare gain from extending education is, under $\lim _{e_{t-1} \rightarrow 0} h^{\prime}\left(e_{t-1}\right)=+\infty$,

$$
\lim _{e_{t-1} \rightarrow 0} h^{\prime}\left(e_{t-1}\right)\left[\alpha^{2}\left(w_{t+1}^{e}\right)^{2} \gamma \bar{\ell}+R_{t+1}^{e} w_{t}\right]=+\infty>R_{t+1}^{e} R_{t}
$$

so that the marginal welfare gain from increasing education exceeds the marginal welfare loss from increasing education, implying that $e_{t-1}=0$ cannot be optimal.

Suppose $e_{t-1}=+\infty$. Then the marginal welfare gain from extending education is, under $\lim _{e_{t-1} \rightarrow+\infty} h^{\prime}\left(e_{t-1}\right)=0$,

$$
\lim _{e_{t-1} \rightarrow+\infty} h^{\prime}\left(e_{t-1}\right)\left[\alpha^{2}\left(w_{t+1}^{e}\right)^{2} h\left(e_{t-1}\right) \gamma \bar{\ell}+R_{t+1}^{e} w_{t}\right]=0<R_{t+1}^{e} R_{t}
$$

so that the marginal welfare gain from increasing education is inferior to the marginal welfare loss from increasing education, implying that $e_{t-1}=+\infty$ cannot be optimal.

Given that the marginal welfare gain from increasing education exceeds the marginal welfare loss from increasing education at $e_{t-1}=0$, and given that the marginal welfare gain from increasing education is inferior to the marginal welfare loss from increasing education when $e_{t-1}$ tends to $+\infty$, it follows, by continuity, that there must exist an interior optimal education level.

Regarding the uniqueness of that optimal education level, note that the derivative of the LHS of the FOC wrt $e_{t-1}$ is:

$$
h^{\prime \prime}\left(e_{t-1}\right)\left[\alpha^{2}\left(w_{t+1}^{e}\right)^{2} h\left(e_{t-1}\right) \gamma \bar{\ell}+R_{t+1}^{e} w_{t}\right]+\left[h^{\prime}\left(e_{t-1}\right)\right]^{2}\left[\alpha^{2}\left(w_{t+1}^{e}\right)^{2} \gamma \bar{\ell}\right]
$$

We can rewrite that expression as:

$$
\left[\alpha^{2}\left(w_{t+1}^{e}\right)^{2} \gamma \bar{\ell}\right]\left[h^{\prime \prime}\left(e_{t-1}\right) h\left(e_{t-1}\right)+\left[h^{\prime}\left(e_{t-1}\right)\right]^{2}\right]+h^{\prime \prime}\left(e_{t-1}\right) R_{t+1}^{e} w_{t}
$$

The first term may be either positive or negative. The second term is negative. Monotonicity of the LHS arises when

$$
\left[h^{\prime \prime}\left(e_{t-1}\right) h\left(e_{t-1}\right)+\left[h^{\prime}\left(e_{t-1}\right)\right]^{2}\right]<0
$$

for all $e_{t-1}$, so that the first term and the second term are both negative. That condition can be written as:

$$
\left|h^{\prime \prime}\left(e_{t-1}\right)\right| h\left(e_{t-1}\right)>\left[h^{\prime}\left(e_{t-1}\right)\right]^{2}
$$

\subsection{Proof of Proposition 2}

The first part of the proposition follows from the FOCs and the conditions for profit maximization of firms in a competitive economy. The second part of the proposition can be proved as follows. 
Suppose $e_{t-1}=0$. Then the marginal welfare gain from extending education is, under $\lim _{e_{t-1} \rightarrow 0} h^{\prime}\left(e_{t-1}\right)=+\infty$ and $\lim _{e_{t-1} \rightarrow 0} \ell^{\prime}\left(e_{t-1}\right)=+\infty$,

$$
\begin{array}{ll}
\lim _{e_{t-1} \rightarrow 0} \quad & h^{\prime}\left(e_{t-1}\right)\left[\alpha^{2}\left(w_{t+1}^{e}\right)^{2} \gamma \ell+R_{t+1}^{e} w_{t}\right] \\
& +\frac{\ell^{\prime}\left(e_{t-1}\right)}{u^{\prime}\left(d_{t+1}\right)}\left[\begin{array}{c}
u\left(d_{t+1}\right)-u^{\prime}\left(d_{t+1}\right) d_{t+1} \\
-u^{\prime}\left(d_{t+1}\right) v_{\ell}\left(z_{t+1}, \ell\right)
\end{array}\right] \\
= & +\infty>R_{t+1}^{e} R_{t}
\end{array}
$$

so that the marginal welfare gain from increasing education exceeds the marginal welfare loss from increasing education, implying that $e_{t-1}=0$ cannot be optimal.

Suppose $e_{t-1}=+\infty$. Then the marginal welfare gain from extending education is, under $\lim _{e_{t-1} \rightarrow+\infty} h^{\prime}\left(e_{t-1}\right)=0$ and $\lim _{e_{t-1} \rightarrow+\infty} \ell^{\prime}\left(e_{t-1}\right)=0$,

$$
\begin{array}{ll}
\lim _{e_{t-1} \rightarrow+\infty} & h^{\prime}\left(e_{t-1}\right)\left[\alpha^{2}\left(w_{t+1}^{e}\right)^{2} h\left(e_{t-1}\right) \gamma \bar{\ell}+R_{t+1}^{e} w_{t}\right] \\
& +\frac{\ell^{\prime}\left(e_{t-1}\right)}{u^{\prime}\left(d_{t+1}\right)}\left[\begin{array}{c}
u\left(d_{t+1}\right)-u^{\prime}\left(d_{t+1}\right) d_{t+1} \\
-u^{\prime}\left(d_{t+1}\right) v_{\ell}\left(z_{t+1}, \bar{\ell}\right)
\end{array}\right] \\
= & 0<R_{t+1}^{e} R_{t}
\end{array}
$$

so that the marginal welfare gain from increasing education is inferior to the marginal welfare loss from increasing education, implying that $e_{t-1}=+\infty$ cannot be optimal.

Given that the marginal welfare gain from increasing education exceeds the marginal welfare loss from increasing education at $e_{t-1}=0$, and given that the marginal welfare gain from increasing education is inferior to the marginal welfare loss from increasing education when $e_{t-1}$ tends to $+\infty$, it follows, by continuity, that there must exist an interior optimal education level.

Regarding the uniqueness of that optimal education level, note that the derivative of the LHS of the FOC wrt $e_{t-1}$ is:

$$
\begin{aligned}
& h^{\prime \prime}\left(e_{t-1}\right)\left[\alpha^{2}\left(w_{t+1}^{e}\right)^{2} h\left(e_{t-1}\right) \gamma \ell\left(e_{t-1}\right)+R_{t+1}^{e} w_{t}\right] \\
& +h^{\prime}\left(e_{t-1}\right)\left[\alpha^{2}\left(w_{t+1}^{e}\right)^{2} h^{\prime}\left(e_{t-1}\right) \gamma \ell\left(e_{t-1}\right)+\alpha^{2}\left(w_{t+1}^{e}\right)^{2} h\left(e_{t-1}\right) \gamma \ell^{\prime}\left(e_{t-1}\right)\right] \\
& +\ell^{\prime \prime}\left(e_{t-1}\right)\left[d_{t+1}\left(\frac{1}{F^{R}}-1\right)-v_{\ell}\left(z_{t+1}, \ell\left(e_{t-1}\right)\right)\right] \\
& +\ell^{\prime}\left(e_{t-1}\right)\left[-v_{\ell \ell}\left(z_{t+1}, \ell\left(e_{t-1}\right)\right) \ell^{\prime}\left(e_{t-1}\right)-v_{\ell z}\left(z_{t+1}, \ell\left(e_{t-1}\right)\right) z_{t+1}\left(\frac{h^{\prime}\left(e_{t-1}\right)}{h\left(e_{t-1}\right)}+\frac{\ell^{\prime}\left(e_{t-1}\right)}{\ell\left(e_{t-1}\right)}\right)\right] \\
& +\ell^{\prime}\left(e_{t-1}\right)\left(\frac{1}{F^{R}}-1\right) \frac{\partial d_{t+1}}{\partial e_{t-1}}
\end{aligned}
$$

For the fourth term of $(83)$, since $v_{\ell}(\cdot)=-\frac{z^{2}}{2 \gamma \ell^{2}},-v_{\ell \ell}(\cdot)-v_{\ell z}(\cdot) \cdot \frac{z}{\ell}=-\frac{z^{2}}{\gamma \ell^{3}}+$ $\frac{z}{\gamma \ell^{2}} \cdot \frac{z}{\ell}=0$. Taking account of $z_{t+1}=\alpha w_{t+1}^{e} h\left(e_{t-1}\right) \gamma \ell(e)$, the fourth term is 
equal to $-\ell^{\prime}\left(e_{t-1}\right) v_{\ell z}\left(z_{t+1}, \ell\left(e_{t-1}\right)\right) z_{t+1} \frac{h^{\prime}\left(e_{t-1}\right)}{h\left(e_{t-1}\right)}=\alpha^{2}\left(w_{t+1}^{e}\right)^{2} h\left(e_{t-1}\right) h^{\prime}\left(e_{t-1}\right) \gamma \ell^{\prime}\left(e_{t-1}\right)$.

Therefore, (83) can be rewritten as:

$$
\begin{aligned}
& \alpha^{2}\left(w_{t+1}^{e}\right)^{2} \gamma\left[h^{\prime \prime}\left(e_{t-1}\right) h\left(e_{t-1}\right) \ell\left(e_{t-1}\right)+\left(h^{\prime}\left(e_{t-1}\right)\right)^{2} \ell\left(e_{t-1}\right)+2 h^{\prime}\left(e_{t-1}\right) h\left(e_{t-1}\right) \ell^{\prime}\left(e_{t-1}\right)\right] \\
& +h^{\prime \prime}\left(e_{t-1}\right) R_{t+1}^{e} w_{t} \\
& +\ell^{\prime \prime}\left(e_{t-1}\right)\left[d_{t+1}\left(\frac{1}{F^{R}}-1\right)-v_{\ell}\left(z_{t+1}, \ell\left(e_{t-1}\right)\right)\right] \\
& +\ell^{\prime}\left(e_{t-1}\right)\left(\frac{1}{F^{R}}-1\right) \frac{\partial d_{t+1}}{\partial e_{t-1}}
\end{aligned}
$$

The second term is negative. The third term is negative when $\frac{1}{F^{R}}>1$. For the fourth term, $d_{t+1}=\frac{z_{t+1} \alpha w_{t+1}^{e} h\left(e_{t-1}\right)-v\left(z_{t+1}, \ell\left(e_{t-1}\right)\right)+R_{t+1} s_{t}}{\ell\left(e_{t-1}\right)}=\frac{\alpha^{2}\left(w_{t+1}^{e}\right)^{2}\left(h\left(e_{t-1}\right)\right)^{2} \gamma}{2}+$ $\frac{R_{t+1}^{e} s_{t}}{\ell\left(e_{t-1}\right)}$. At this point we need to take account that $e_{t-1}$ changes $s_{t}$ through $-u^{\prime}\left(w_{t} h\left(e_{t-1}\right)-e_{t-1} R_{t}-s_{t}\right)+R_{t+1}^{e} u^{\prime}\left(\frac{\alpha^{2}\left(w_{t+1}^{e}\right)^{2}\left(h\left(e_{t-1}\right)\right)^{2} \gamma}{2}+\frac{R_{t+1}^{e} s_{t}}{\ell\left(e_{t-1}\right)}\right)=0$. Making use of $R_{t}-w_{t} h^{\prime}\left(e_{t-1}\right)=\frac{1}{R_{t+1}^{e}}\left[\alpha^{2}\left(w_{t+1}^{e}\right)^{2} h^{\prime}\left(e_{t-1}\right) h\left(e_{t-1}\right) \gamma \ell\left(e_{t-1}\right)+\ell^{\prime}\left(e_{t-1}\right) d_{t+1}\left(\frac{1}{F^{R}}-1\right)\right.$ $-\ell^{\prime}\left(e_{t-1}\right) v_{\ell}(z, \ell(e))$, we have:

$$
\begin{aligned}
& \frac{\partial s_{t+1}}{\partial e_{t-1}}=\quad-\frac{\ell\left(e_{t-1}\right)}{R_{t+1}^{e}} \alpha^{2}\left(w_{t+1}^{e}\right)^{2} h^{\prime}\left(e_{t-1}\right) h\left(e_{t-1}\right) \gamma \\
& +\frac{\ell^{\prime}\left(e_{t-1}\right)}{-u^{\prime \prime}\left(c_{t}\right)-\frac{\left(R_{t+1}^{e}\right)^{2}}{\ell\left(e_{t-1}\right)} u^{\prime \prime}\left(d_{t+1}\right)}\left[\begin{array}{l}
\frac{u^{\prime \prime}\left(c_{t}\right)}{R_{t+1}^{e}}\left(d_{t+1}\left(\frac{1}{F^{R}}-1\right)-v_{\ell}\left(z, \ell\left(e_{t-1}\right)\right)\right) \\
-\frac{\left(R_{t+1}^{e}\right)^{2} s_{t} u^{\prime \prime}\left(d_{t+1}\right)}{\left(\ell\left(e_{t-1}\right)\right)^{2}}
\end{array}\right], \\
& \frac{\partial d_{t+1}}{\partial e_{t-1}}=\quad \alpha^{2}\left(w_{t+1}^{e}\right)^{2} h^{\prime}\left(e_{t-1}\right) h\left(e_{t-1}\right) \gamma+\frac{R_{t+1}^{e}}{\ell\left(e_{t-1}\right)}\left(\frac{\partial s_{t}}{\partial e_{t-1}}-\frac{\ell^{\prime}\left(e_{t-1}\right)}{\ell\left(e_{t-1}\right)} s_{t}\right) \\
& =\frac{\ell^{\prime}\left(e_{t-1}\right)}{-u^{\prime \prime}\left(c_{t}\right)-\frac{\left(R_{t+1}^{e}\right)^{2}}{\ell\left(e_{t-1}\right)} u^{\prime \prime}\left(d_{t+1}\right)}\left[\begin{array}{l}
\frac{u^{\prime \prime}\left(c_{t}\right)}{\ell\left(e_{t-1}\right)}\left(d_{t+1}\left(\frac{1}{F^{R}}-1\right)-v_{\ell}\left(z, \ell\left(e_{t-1}\right)\right)\right) \\
+\frac{R_{t+1}^{e} u^{\prime \prime}\left(c_{t}\right) s_{t}}{\left(\ell\left(e_{t-1}\right)\right)^{2}}
\end{array}\right] \\
& <\quad 0 \text {. }
\end{aligned}
$$

Hence, a sufficient condition for the uniqueness of the optimal education level is:

$$
h^{\prime \prime}\left(e_{t-1}\right) h\left(e_{t-1}\right) \ell\left(e_{t-1}\right)+\left(h^{\prime}\left(e_{t-1}\right)\right)^{2} \ell\left(e_{t-1}\right)+2 h^{\prime}\left(e_{t-1}\right) h\left(e_{t-1}\right) \ell^{\prime}\left(e_{t-1}\right)<0
$$

That condition, which guarantees the monotonicity of the LHS, can be written as:

$$
\left|h^{\prime \prime}\left(e_{t-1}\right)\right| h\left(e_{t-1}\right) \ell\left(e_{t-1}\right)>\left(h^{\prime}\left(e_{t-1}\right)\right)^{2} \ell\left(e_{t-1}\right)+2 h^{\prime}\left(e_{t-1}\right) h\left(e_{t-1}\right) \ell^{\prime}\left(e_{t-1}\right)
$$




\subsection{Proof of Proposition 3}

Under a stationary equilibrium with perfect foresight, we have $k_{t+1}^{e}=k_{t+1}=$ $k_{t}=k$, and $e_{t}=e_{t-1}=e_{t-2}=e$, so that we have:

$$
\begin{aligned}
k & =\frac{S(w(k), R(k), w(k), R(k))-e}{h(e)+\alpha^{2} w(k)[h(e)]^{2} \gamma \bar{\ell}} \equiv \frac{\tilde{S}(k)-e}{h(e)+\alpha^{2} w(k)[h(e)]^{2} \gamma \bar{\ell}} \\
e & \equiv e(w(k), R(k), w(k), R(k)) \equiv \bar{e}(k)
\end{aligned}
$$

A stationary equilibrium with perfect foresight is a pair $(e, k)$ satisfying those two conditions. To examine the existence of such a pair, let us study some properties of those two relations.

Take the first one. This equality can be rewritten as:

$$
\begin{aligned}
k & =\frac{\tilde{S}(k)-e}{h(e)+\alpha^{2} w(k)[h(e)]^{2} \gamma \bar{\ell}} \\
& \Longleftrightarrow k\left[h(e)+\alpha^{2} w(k)[h(e)]^{2} \gamma \bar{\ell}\right]=\tilde{S}(k)-e \\
& \Longleftrightarrow h(e)\left[1+\alpha^{2} w(k)[h(e)] \gamma \bar{\ell}\right]=\frac{\tilde{S}(k)-e}{k}
\end{aligned}
$$

$\frac{\tilde{S}(k)-e}{k}$ is a ratio: saving per young worker net of borrowing for education investment, divided by capital per effective labor unit. Denote the solution of $h(e)\left[1+\alpha^{2} w(k)[h(e)] \gamma \bar{\ell}\right]=\frac{\tilde{S}(k)-e}{k}$ as $e=\check{e}(k)$, that is, the level of $e$ such that $h(e)\left[1+\alpha^{2} w(k)[h(e)] \gamma \bar{\ell}\right]=\frac{\tilde{S}(k)-e}{k}$ holds for a given $k$. Suppose that the level of $k$ such that $\check{e}(k)=0$ is unique and positive, and $\check{e}^{\prime}(k)<0$.

Take now (87). We first show that $\bar{e}^{\prime}(k)>0$. Evaluated at the steady-state, equation (32) is:

$$
w h^{\prime}(e)\left[R+\alpha^{2} w h(e) \gamma \bar{\ell}\right]-R^{2} \equiv \Delta=0 .
$$

We can compute:

$$
\frac{d \bar{e}}{d k}=\frac{\Delta_{k}}{-\Delta_{e}}=\frac{h^{\prime}(e)\left(\alpha^{2} 2 w(k) w^{\prime}(k) h(e) \gamma \bar{\ell}+R w^{\prime}(k)+f^{\prime \prime}(k) w(k)\right)-2 f^{\prime \prime}(k) R}{-\Delta_{e}}
$$

$\Delta_{e}<0$ because of the second-order condition, so that the denominator of the above formula is positive. As for the numerator, $w^{\prime}(k)=-k f^{\prime \prime}(k)>0$ from (11), and $-f^{\prime \prime}(k)>0$. Also, $h^{\prime}(e) f^{\prime \prime}(k) w(k)-f^{\prime \prime}(k) R=f^{\prime \prime}(k)\left[h^{\prime}(e) w(k)-R\right]$. From (88), $h^{\prime 2} w^{2} h^{\prime}(e) h(e) \gamma \bar{\ell} / R<0$, so that $h^{\prime}(e) f^{\prime \prime}(k) w(k)-f^{\prime \prime}(k) R>0$. We then conclude that $d \bar{e} / d k>0$.

We next show that $\bar{e}(0)=0$. The formula of $\Delta=0$ can be rearranged to:

$$
h^{\prime}(e) \alpha^{2}(w(k))^{2} h(e) \gamma \bar{\ell}=f^{\prime}(k)\left[f^{\prime}(k)-h^{\prime}(e) w(k)\right] .
$$

$\lim _{k \rightarrow 0} w(k)=\lim _{k \rightarrow 0}\left(f(k)-f^{\prime}(k) k\right)=0$. If $\lim _{k \rightarrow 0} f^{\prime}(k)=+\infty$, then the above equality cannot hold at $k=0$ unless $e=0$. So $\bar{e}(0)=0$ has to be the 
case. We therefore obtained an increasing relationship between $e$ and $k$, passing through $(k, e)=(0,0)$.

Let $k^{a}>0$ be the value such that $\check{e}\left(k^{a}\right)=0$. Given $k^{a}>0$ and $\bar{e}^{\prime}(k)>0$, it follows that $\check{e}\left(k^{a}\right)<\bar{e}\left(k^{a}\right)$. On the other hand, by $\check{e}^{\prime}(0)>\bar{e}^{\prime}(0)$ and $\check{e}(0) \geq 0$, there must exist $\bar{k}$ such that $\check{e}(\bar{k})>\check{e}(\bar{k})$. Hence, by continuity, there must exist an intersection of $e=\bar{e}(k)$ and $e=\check{e}(k)$, namely, a pair $(k, e)$ satisfying both conditions. Hence we proved existence of a stationary equilibrium with perfect foresight.

\subsection{Proof of Proposition 4}

Under a stationary equilibrium with perfect foresight, we have $k_{t+1}^{e}=k_{t+1}=$ $k_{t}=k$, and $e_{t}=e_{t-1}=e_{t-2}=e$, so that we have:

$$
\begin{aligned}
k & =\frac{\hat{s}(w(k), R(k), w(k), R(k), e)-e}{h(e)+\alpha^{2} w(k)[h(e)]^{2} \gamma \ell(e)}=\frac{\tilde{s}(k, e)-e}{h(e)+\alpha^{2} w(k)[h(e)]^{2} \gamma \ell(e)} \\
e & =\hat{e}(w(k), R(k), w(k), R(k), \tilde{s}(k, e))=\tilde{e}(k, \tilde{s}(k, e))
\end{aligned}
$$

where $\tilde{s}(k, e) \equiv \hat{s}(w(k), R(k), w(k), R(k), e)$.

To examine the existence of such a pair, let us study some properties of those two relations. Take the first one. This equality can be rewritten as:

$$
\begin{aligned}
k & =\frac{\tilde{s}(k, e)-e}{h(e)+\alpha^{2} w(k)[h(e)]^{2} \gamma \ell(e)} \\
& \Longleftrightarrow k\left[h(e)+\alpha^{2} w(k)[h(e)]^{2} \gamma \ell(e)\right]=\tilde{s}(k, e)-e \\
& \Longleftrightarrow h(e)\left[1+\alpha^{2} w(k) h(e) \gamma \ell(e)\right]=\frac{\tilde{s}(k, e)-e}{k}
\end{aligned}
$$

Let us denote the solution of $h(e)\left[1+\alpha^{2} w(k) h(e) \gamma \ell(e)\right]=\frac{\tilde{s}(k, e)-e}{k}$ as $e=\check{e}(k)$, that is, the level of $e$ such that $h(e)\left[1+\alpha^{2} w(k) h(e) \gamma \ell(e)\right]=\frac{\tilde{s}(k, e)-e}{k}$ holds for a given $k$.

Take the second relation. That equality can be rewritten as:

$$
e=\tilde{e}(k, \tilde{s}(k, e))
$$

Denote by $e=\bar{e}(k)$ the solution of $e=\tilde{e}(k, \tilde{s}(k, e))$, that is, the level of $e$ such that $e=\tilde{e}(k, \tilde{s}(k, e))$ holds for a given $k$. There are good reasons to believe that $\bar{e}(k)$ is increasing in $k$. Clearly, a higher $k$ implies a higher wage, and thus higher marginal returns from education, as well as a lower interest factor, implying a lower marginal cost of education. Assuming that $\bar{e}^{\prime}(k)>0$ and $\bar{e}(0)=0, \bar{e}(k)$ is an increasing relationship passing through $(k, e)=(0,0)$.

Let $k^{a}>0$ be the value such that $\check{e}\left(k^{a}\right)=0$. Given $k^{a}>0$ and $\bar{e}^{\prime}(k)>0$, it follows that $\check{e}\left(k^{a}\right)<\bar{e}\left(k^{a}\right)$. On the other hand, by $\check{e}^{\prime}(0)>\bar{e}^{\prime}(0)$ and $\check{e}(0) \geq 0$, there must exist $\bar{k}$ such that $\check{e}(\bar{k})>\check{e}(\bar{k})$. Hence, by continuity, there must exist an intersection of $e=\bar{e}(k)$ and $e=\check{e}(k)$, namely, a pair $(k, e)$ satisfying 
both conditions. Hence we proved existence of a stationary equilibrium with perfect foresight.

\subsection{Proof of Proposition 8}

The formula of $\Delta_{e}$ is (83) in the proof of Proposition 2, evaluated at the stationary equilibrium. When $\ell^{\prime}(e)=0$, the value of $-\Delta_{e}$ is equivalent to the denominator of (50).

Recall that $z=\alpha w h(e) \gamma \ell(e)$, and also our assumption that $F^{R}$ is constant. We have:

$$
\begin{aligned}
\Delta_{\lambda}= & h^{\prime}(e) w^{2} \alpha^{2} h(e) \gamma \ell(e)+\ell^{\prime}(e)\left(\frac{1}{F^{R}}-1\right)\left(d+\lambda \frac{\partial d}{\partial \lambda}\right)-\ell^{\prime}(e) v_{\ell}(z, \lambda \ell(e)) \\
& -\ell^{\prime}(e)\left[\lambda \ell(e) v_{\ell \ell}(z, \lambda \ell(e))+z v_{\ell z}(z, \lambda \ell(e)] .\right.
\end{aligned}
$$

As for the last term in the above equation, since $v_{\ell}(\cdot)=-\frac{z^{2}}{2 \gamma \ell^{2}}, v_{\ell \ell}(\cdot) \cdot \ell=\frac{z^{2}}{\gamma \ell^{2}}$ and $v_{\ell z}(\cdot) \cdot z=-\frac{z^{2}}{\gamma \ell^{2}}$, so that $\lambda \ell(e) v_{\ell \ell}(z, \lambda \ell(e))+z v_{\ell z}(z, \lambda \ell(e))=0$. Therefore, the above equation is identical to the numerator of (56).

We have $d=\frac{z \alpha w h(e)-v(z, \ell(e))+R s}{\ell(e)}=\frac{\alpha^{2} w^{2}(h(e))^{2} \gamma}{2}+\frac{R s}{\lambda \ell(e)}$. Taking account that $\lambda$ changes $s$ through $-u^{\prime}(w h(e)-e R-s)+R u^{\prime}\left(\frac{\alpha^{2} w^{2}(h(e))^{2} \gamma}{2}+\frac{R s}{\lambda \ell(e)}\right)=0$,

$$
\frac{\partial s}{\partial \lambda}=\frac{\frac{R^{2}}{\lambda \ell(e)} u^{\prime \prime}(d)}{u^{\prime \prime}(c)+\frac{(R)^{2}}{\lambda \ell(e)} u^{\prime \prime}(d)} \frac{s}{\lambda}
$$

and thus,

$$
\frac{\partial d}{\partial \lambda}=\frac{R}{\lambda \ell(e)}\left(\frac{\partial s}{\partial \lambda}-\frac{s}{\lambda}\right)=\frac{-u^{\prime \prime}(c)}{u^{\prime \prime}(c)+\frac{(R)^{2}}{\lambda \ell(e)} u^{\prime \prime}(d)} \frac{R s}{\lambda^{2} \ell(e)}<0 .
$$

Therefore,

$$
d+\lambda \frac{\partial d}{\partial \lambda} \geq \frac{R s}{\lambda \ell(e)}+\lambda \frac{\partial d}{\partial \lambda}=\frac{R s}{\lambda \ell(e)} \frac{\frac{R^{2}}{\lambda \ell(e)} u^{\prime \prime}(d)}{u^{\prime \prime}(c)+\frac{(R)^{2}}{\lambda \ell(e)} u^{\prime \prime}(d)}>0 .
$$

Hence we conclude that all the terms in the numerator of (56) are positive. 